\title{
Multifunctional magnetic iron oxide nanoparticles: diverse synthetic approaches, surface modifications, cytotoxicity towards biomedical and industrial applications
}

\author{
Subramanian Natarajan ${ }^{1}$, Kannan Harini ${ }^{2}$, Gnana Prakash Gajula ${ }^{3}$, Bruno Sarmento $4,5,6,7^{*}$ (D), \\ Maria Teresa Neves-Petersen ${ }^{8}$ and Viruthachalam Thiagarajan ${ }^{{ }^{*}}$ (D)
}

\begin{abstract}
Magnetic iron oxide nanoparticles (MIONPs) play a major role in the emerging fields of nanotechnology to facilitate rapid advancements in biomedical and industrial platforms. The superparamagnetic properties of MIONPs and their environment friendly synthetic methods with well-defined particle size have become indispensable to obtain their full potential in a variety of applications ranging from cellular to diverse areas of biomedical science. Thus, the broadened scope and need for MIONPs in their demanding fields of applications required to be highlighted for a comprehensive understanding of their state-of-the-art. Many synthetic methods, however, do not entirely abolish their undesired cytotoxic effects caused by free radical production and high iron dosage. In addition, the agglomeration of MIONPs has also been a major problem. To alleviate these issues, suitable surface modification strategies adaptive to MIONPs has been suggested not only for the effective cytotoxicity control but also to minimize their agglomeration. The surface modification using inorganic and organic polymeric materials would represent an efficient strategy to utilize the diagnostic and therapeutic potentials of MIONPs in various human diseases including cancer. This review article elaborates the structural and magnetic properties of MIONPs, specifically magnetite, maghemite and hematite, followed by the important synthetic methods that can be exploited for biomedical approaches. The in vivo cytotoxic effects and the possible surface modifications employed to eliminate the cytotoxicity thereby enhancing the nanoparticle efficacy are also critically discussed. The roles and applications of surface modified MIONPs in medical and industrial platforms have been described for the benefits of global well-being.
\end{abstract}

Keywords: Magnetic iron oxide nanoparticles (MIONPs), Synthetic methods, Cytotoxicity, Surface modification, Applications

\section{Introduction}

The specific diverse applications of nanoparticles arise from the physical characteristics of the nanomaterials they are comprised of. Nanomaterials often reveal novel

\footnotetext{
*Correspondence: bruno.sarmento@ineb.up.pt; vthiags@gmail.com: v.thiagarajan@bdu.ac.in

${ }^{1}$ Photonics and Biophotonics Lab, School of Chemistry, Bharathidasan University, Tiruchirappalli 620 024, India

${ }^{4}$ INEB-Instituto de Engenharia Biomédica, University of Porto, Rua Alfredo Allen 208, 4200-135 Porto, Portugal

Full list of author information is available at the end of the article
}

and distinct electrical, optical, magnetic and chemical properties as against their bulk materials [1]. Nanomaterials are categorized as 'closely packed materials' and 'nanodispersions' which include "nanostructured" materials, i.e., an isotropic material with a macroscopic composition consisting of compact nanometre-sized units such as the fundamental replicating structural and functional elements [2]. Nanoparticles are pertained to make revolutionary technological changes in escalating the standards and quality of human health with transformative and innovative diagnostic, therapeutic and even 
theranostic tools (that combine the diagnostic and therapeutic approaches in a single agent) [3].

Magnetic nanoparticles (MNPs) can be exploited for desired applications under the manipulation of an external magnetic field. It can be synthesized with a cost effective and wide spread material like iron as in the case of magnetic iron oxide nanoparticles (MIONPs) which is least toxic and biodegradable [4-10]. Nanomaterials containing iron are derived from iron nanoalloys, zero valent iron and oxides like ferrites, etc. Iron naturally exists in the environment as $\mathrm{Fe}(\mathrm{II})$ and $\mathrm{Fe}(\mathrm{III})$ oxides. Iron oxides refer to oxides, hydroxides and oxy-hydroxides contains both $\mathrm{Fe}(\mathrm{II}) / \mathrm{Fe}(\mathrm{III})$ cations and $\mathrm{O}^{2-} / \mathrm{OH}^{-}$anions. Sixteen pure phases of iron oxides are known till date. These includes $\mathrm{Fe}(\mathrm{OH})_{2}, \mathrm{Fe}(\mathrm{OH})_{3}, \mathrm{Fe}_{3} \mathrm{O}_{4}, \mathrm{Fe}_{5} \mathrm{HO}_{8} .4 \mathrm{H}_{2} \mathrm{O}, \mathrm{FeO}$, four polymorphs of $\mathrm{Fe}_{2} \mathrm{O}_{3}$ and five of $\mathrm{FeOOH}[11,12]$. Characteristics of these oxide compounds are inclusive of divalent and trivalent states of the iron, relatively low solubility and their brilliant colours. Among the iron oxides, $\mathrm{Fe}_{3} \mathrm{O}_{4}$ and $\gamma-\mathrm{Fe}_{2} \mathrm{O}_{3}$ have received wide attention and acceptance due to their tunable size-dependent magnetic properties $[13,14]$.

During the last decade, researchers have focused their priority towards developing efficient methods for the synthesis of MIONPs to address their growing demands with desired physical and chemical properties. This clearly reflects the increasing need for various synthetic approaches to obtain well-crystallized and well-defined MIONPs $[15,16]$. After synthesis, MIONPs need appropriate surface modifications to make them more compatible for their respective applications with suitable molecular conjugation and functionalization methods [17]. Therefore, surface modification becomes a critical post-synthetic step for preparing compatible and stable MIONPs. A schematic representation that summarizes the development of MIONPs is presented in Fig. 1.

At present, MIONPs are widely used in biomedical applications such as magnetic bio-separation and detection of biological entities (for example cells, proteins, nucleic acids, enzymes, bacteria, virus, etc.). Further MIONPs are implicated in clinical diagnosis like magnetic resonance imaging and therapy such as targeted drug delivery, magnetic fluid hyperthermia, and biological labels for anticancer therapy, catalysis, wastewater treatment and oil recovery. The main reasons for the specific choice of these nanoparticles in such applications are due to the controllable size ranging from few nanometers to tens of nanometers thereby providing the dimensions that are either comparable or closer to those of a protein $(5-50 \mathrm{~nm})$, a virus $(20-450 \mathrm{~nm})$, or even a gene $(10-$ $100 \mathrm{~nm}$ long and $2 \mathrm{~nm}$ wide). So that it could efficiently get into the close vicinity of a biological entity as well as the therapeutic target of interest [18]. In addition to that,
MIONPs can be directed in the presence of an external magnetic field gradient, since it obeys Coulomb's law for magnetism. To highlight the industrial demands of MIONPs, one needs to understand the exposure of dyes and heavy metals in drinking water that causes undesirable toxicity to living beings. In recent years, a great deal of interest has been developed in using MIONPs for the effective removal of dyes and heavy metals during wastewater treatment [19].

\section{General structural properties of iron oxides}

There are eight different iron oxides that are well known in nature [20], among them magnetite $\left(\mathrm{Fe}_{3} \mathrm{O}_{4}\right)$, maghemite $\left(\gamma-\mathrm{Fe}_{2} \mathrm{O}_{3}\right)$ and hematite $\left(\alpha-\mathrm{Fe}_{2} \mathrm{O}_{3}\right)$ shows the unique magnetic properties and they have different polymorphic forms and undergo temperature induced phase transition. Magnetite and maghemite are ideal materials for industrial and biomedical applications. Both have reusable advantage over other iron oxides due to their unique magnetic, catalytic and biochemical properties. The physical properties of $\mathrm{Fe}_{3} \mathrm{O}_{4}, \gamma-\mathrm{Fe}_{2} \mathrm{O}_{3}$ and $\alpha-\mathrm{Fe}_{2} \mathrm{O}_{3}$ are presented in Table 1 [20-22].

\section{Magnetite}

$\mathrm{Fe}_{3} \mathrm{O}_{4}$ is derived from various sources such as black iron oxide, magnetic iron ore, loadstone, ferrous ferrite and Hercules stone. $\mathrm{Fe}_{3} \mathrm{O}_{4}$ has face centered cubic spinel structure with both divalent and trivalent iron in it. All of the $\mathrm{Fe}^{2+}$ ions reside in half of the octahedral sites whereas the $\mathrm{Fe}^{3+}$ ions are divided evenly across the remaining available octahedral and the tetrahedral sites $[20,21]$. It reveals strong magnetism when compared to other transition metal oxides. The saturation magnetization value for bulk material is $92 \mathrm{emu} / \mathrm{g}$. It offers a high surface area for adsorption and immobilization of molecules or drugs for our interest. It can be controlled and easily separated by a magnetic field and further applicable for subsequent reuse.

\section{Maghemite}

$\gamma-\mathrm{Fe}_{2} \mathrm{O}_{3}$ is present in soils as a weathering product of $\mathrm{Fe}_{3} \mathrm{O}_{4} \cdot \gamma-\mathrm{Fe}_{2} \mathrm{O}_{3}$ has a cubic spinel crystal structure with each unit contains $32 \mathrm{O}^{2-}$ and $21^{1 / 2} \mathrm{Fe}^{3+}$ ions with $2 \frac{1}{2}$ vacancies. Oxygen anions lead to a cubic close-packed arrangement whereas ferric ions are spread over tetrahedral and octahedral sites [21, 23]. Since, the atomic radii of $\mathrm{Fe}^{3+}$ ion is smaller than the $\mathrm{Fe}^{2+}$ ion, the unit cell parameter of $\gamma-\mathrm{Fe}_{2} \mathrm{O}_{3}$ is smaller than $\mathrm{Fe}_{3} \mathrm{O}_{4}$. It also shows strong magnetism with the saturation magnetization value of $78 \mathrm{emu} / \mathrm{g}$ for the bulk material. 


\section{Iron precursors \& \\ Alkali source}

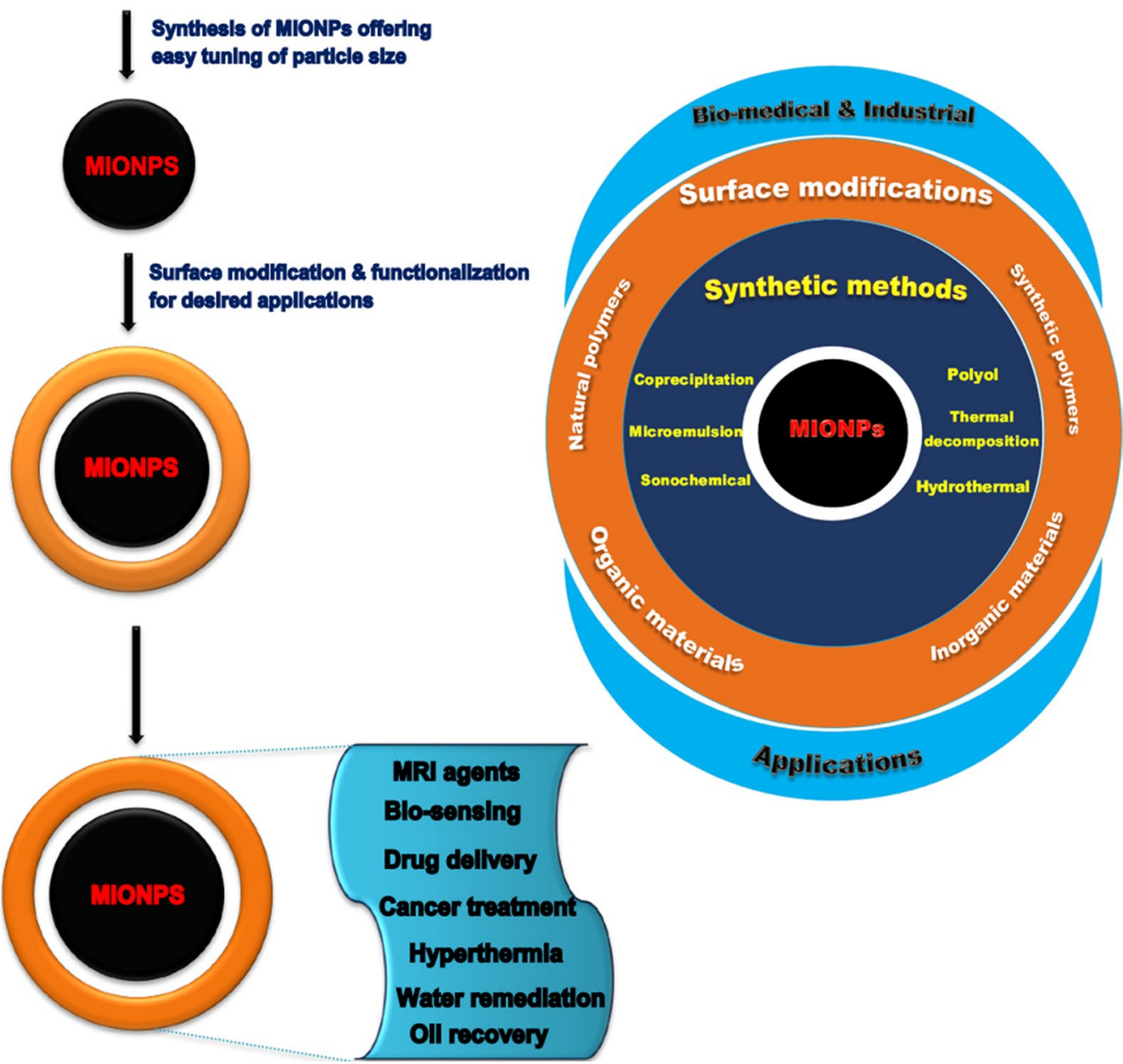

Fig. 1 A schematic representation of the development of MIONPs

\section{Hematite}

$\alpha-\mathrm{Fe}_{2} \mathrm{O}_{3}$ is the most well-known of the iron oxides and is common in rocks and soils namely ferric oxide, iron sesquioxide, red ochre, specularite, specular iron ore, kidney ore and martite. $\alpha-\mathrm{Fe}_{2} \mathrm{O}_{3}$ is blood red in colour, and black or grey in crystalline state. In $\alpha-\mathrm{Fe}_{2} \mathrm{O}_{3}$, twothirds of the octahedral sites are occupied by $\mathrm{Fe}^{3+}$ ions with an ideal hexagonal close-packed oxygen lattice. It is extensively used in catalysts, in the preparation of pigments and gas sensors due to its cost-effective and corrosion resistant. It can also be act as a starting material for the synthesis of $\mathrm{Fe}_{3} \mathrm{O}_{4}$ and $\gamma-\mathrm{Fe}_{2} \mathrm{O}_{3}$, which extensively used in technological applications during recent years [23].

\section{Magnetic properties of iron oxide structures}

Iron shows excellent magnetic properties; if we consider it as a single atom under the influence of magnetic field it tends to align parallel to the field and so exhibit paramagnetic behaviour. But as a bulk material, it consists of several iron atoms confined in a very small space. Therefore, the presence of multiple atoms leads to the formation of various domains and inside which the spin states are usually parallel to each other but not aligned parallel to the applied magnetic field or aligned in a single direction. Thus, when all the spin states in a given domain (and also all the domains) aligned in a single direction parallel to the applied magnetic field it is called ferromagnetic state. If the spins are aligned anti-parallel to each other which in turn cancels itself with the overall net magnetic moment of zero units (or very close to zero), the states 
Table 1 Physical properties of important iron oxides [20-22]

\begin{tabular}{|c|c|c|c|}
\hline Properties & Magnetite & Maghemite & Hematite \\
\hline Molecular formula & $\mathrm{Fe}_{3} \mathrm{O}_{4}$ & $\gamma-\mathrm{Fe}_{2} \mathrm{O}_{3}$ & $\mathrm{a}-\mathrm{Fe}_{2} \mathrm{O}_{3}$ \\
\hline Density $\left(\mathrm{g} / \mathrm{cm}^{3}\right)$ & 5.18 & 4.87 & 5.26 \\
\hline Melting point $\left({ }^{\circ} \mathrm{C}\right)$ & 1583-1597 & - & 1350 \\
\hline Hardness & 5.5 & 5 & 6.5 \\
\hline Type of magnetism & Ferrimagnetic & Ferrimagnetic & Weakly ferromagnetic or antiferromagnetic \\
\hline Curie temperature $(\mathrm{K})$ & 850 & $820-986$ & 956 \\
\hline $\begin{array}{l}\text { The saturation magnetization (Ms) at } \\
300 \mathrm{~K}\left(\mathrm{~A}-\mathrm{m}^{2} / \mathrm{kg}\right)\end{array}$ & $92-100$ & $60-80$ & 0.3 \\
\hline $\begin{array}{l}\text { Standard free energy of formation } \Delta \mathrm{G}_{f}^{\circ} \\
(\mathrm{kJ} / \mathrm{mol})\end{array}$ & -1012.6 & -711.1 & -742.7 \\
\hline Crystallographic system & Cubic & Cubic or tetragonal & Rhombohedral, hexagonal \\
\hline Structure type & Inverse spinel & Defect spinel & Corundum \\
\hline Space group & Fd3 m & $\begin{array}{l}\mathrm{P}_{4} 32 \text { (Cubic), } \\
\mathrm{P}_{1} 2_{1} 2 \text { (tetragonal) }\end{array}$ & R3c (hexagonal) \\
\hline Lattice parameter (nm) & $a=0.8396$ & $\begin{array}{l}a=0.83474 \text { (cubic) } \\
a=0.8347, c=2.501 \text { (tetragonal) }\end{array}$ & $\begin{array}{l}a=0.5034, c=1.375 \text { (hexagonal) } \\
a_{R h}=0.5427, a=55.3^{\circ} \text { (rhombohedral) }\end{array}$ \\
\hline
\end{tabular}

are known as anti-ferromagnetic states. On the other hand, if there is a presence of partial anti-parallel states in the given material, the overall magnetic moment will be less than the calculated value and such states are known as ferrimagnetic states $[23,24]$. The ordering of spins in ferromagnetic, antiferromagnetic, ferrimagnetic and paramagnetic materials are presented in Fig. 2a.

In general, the number of magnetic domains in given magnetic material is directly proportional to the size of the material. Therefore, the reduction in size from bulk to as small as nanometre volume reduces the multidomain material to the single domain material (Fig. 2b). Thus, the presence of single domain confined to a nanometre volume which exhibit superparamagnetic behaviour with coercivity and remanence value close to zero. It is important to know that the coercivity is the reverse magnetic field required to drive the magnetisation to zero while the remanence is the amount of magnetization remains after the applied magnetic field is switched off (i.e. at zero magnetic field). In other words, unlike the bulk ferromagnetic material, the superparamagnetic particle loses its magnetisation immediately after the applied magnetic field is switched off. This is due to the thermal energy overpowers the anisotropic energy barrier. For showing superparamagnetic behaviour the requirement for minimum particle volume is $25 \mathrm{k}_{\mathrm{B}} \mathrm{T} / \mathrm{K}$, where $\mathrm{k}_{\mathrm{B}}$ is the Boltzmann constant, $\mathrm{T}$ is temperature and $\mathrm{K}$ is the anisotropic constant $\left(\mathrm{K}=-1.1 \times 10^{5} \mathrm{erg} / \mathrm{cm}^{3}\right.$ for $\left.\mathrm{Fe}_{3} \mathrm{O}_{4}\right)$. Spherical $\mathrm{Fe}_{3} \mathrm{O}_{4}$ nanoparticles with a particle size less than $26 \mathrm{~nm}$ exhibit superparamagnetic behaviour and their magnetic properties strongly depends on the methods of synthesis. The crystal structure affects coercivity in the order of its respective shape (spheres $<$ cubes $<$ octahedral). $\gamma-\mathrm{Fe}_{2} \mathrm{O}_{3}$ particles of less than $30 \mathrm{~nm}$ size are superparamagnetic at room temperature [25].

Surface modifications by chemical treatments also have a strong affect on the magnetic properties of MIONPs [26]. Among the iron oxides, $\mathrm{Fe}_{3} \mathrm{O}_{4}$ and $\gamma$ - $\mathrm{Fe}_{2} \mathrm{O}_{3}$ are very commonly used for biomedical applications due to their stability, low toxicity and high saturation magnetization value. MIONPs with $10-30 \mathrm{~nm}$ particle size have more chemically active sites on its surface for bioconjugation and high saturation magnetization value for desired applications.

\section{Synthetic methods of MIONPs}

While various synthetic methods offer innovative approaches of controlling the nucleation and NPs growth process, efficient synthetic methods are in need to obtain desired size, structure and exact chemical composition of MIONPs. A lot of efforts have been taken to understand the mechanism of NPs formation in solutions via nucleation and growth [27]. Physical methods include metal evaporation by sputtering, ball milling and electrode deposition. These methods are advantageous since they allow mass production and high-purity nanomaterials but they do not offer a good control on the size and shape of the nanoparticle. Solution phase chemical methods offer effective ways to produce MIONPs because of their precise control over the composition, size and structure of the resultant materials. These chemical methods include co-precipitation, gas-phase deposition, sol-gel method, oxidation method, flow injection, microbials, herbal plants extract, thermal decomposition or reduction, hydrothermal synthesis, laser pyrolysis techniques and herbal extract mediated biosynthesis. In this section 


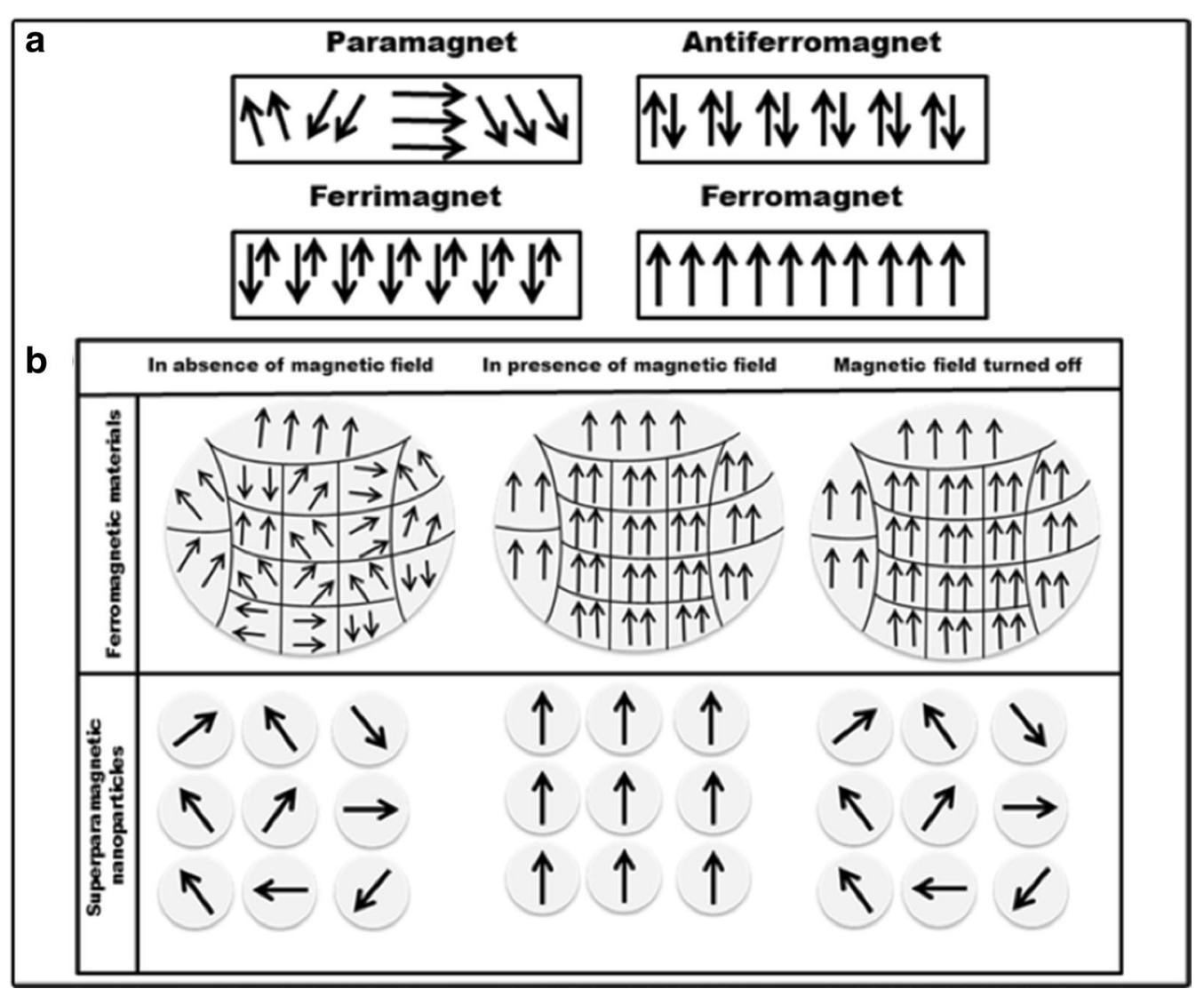

Fig. 2 a The arrangement of spins in different magnetic materials. b Magnetization behaviour of ferromagnetic materials and superparamagentic nanoparticles under the external magnetic field turned on and off

Table 2 Comparison of important synthetic methods used of MIONPs

\begin{tabular}{|c|c|c|c|c|c|}
\hline Method & Size distribution & Shape & Advantages & Limitations & $\begin{array}{l}\text { Magnetic } \\
\text { values } \\
(\text { emu/g) }\end{array}$ \\
\hline Co-precipitation & $\begin{array}{l}\text { 3-100 nm with broad distri- } \\
\text { bution }\end{array}$ & Spherical & $\begin{array}{l}\text { Affordable, rapid and can be } \\
\text { easily scaled up to larger } \\
\text { scale }\end{array}$ & $\begin{array}{l}\text { High polydispersity index } \\
\text { and controlling shape and } \\
\text { size of NPs is challenging }\end{array}$ & $20-50$ \\
\hline $\begin{array}{l}\text { Microemulsion and } \\
\text { reverse microemul- } \\
\text { sions }\end{array}$ & $\begin{array}{l}\text { 4-15 } \mathrm{nm} \text { with narrow distri- } \\
\text { bution }\end{array}$ & Spherical or cubic & $\begin{array}{l}\text { Desired size of the nanoparti- } \\
\text { cles can be obtained by } \\
\text { adjusting the aqueous core } \\
\text { droplet size }\end{array}$ & $\begin{array}{l}\text { Difficult to remove sur- } \\
\text { factants and only small } \\
\text { amounts can be synthe- } \\
\text { sized }\end{array}$ & $>30$ \\
\hline Sonochemical & $\begin{array}{l}20-80 \mathrm{~nm} \text { with broad distri- } \\
\text { bution }\end{array}$ & Spherical & $\begin{array}{l}\text { Use of fewer reagents and } \\
\text { minimal purification steps }\end{array}$ & $\begin{array}{l}\text { Highly specific experimental } \\
\text { device required }\end{array}$ & $20-85$ \\
\hline Polyol & $\begin{array}{l}\text { 10-50 nm with narrow } \\
\text { distribution }\end{array}$ & Cubic & $\begin{array}{l}\text { Easy to control the size and } \\
\text { shape of the } \\
\text { nanoparticles }\end{array}$ & High-temperature required & $50-80$ \\
\hline Thermal decomposition & $\begin{array}{l}\text { 6-80 nm with broad distribu- } \\
\text { tion }\end{array}$ & Spherical & $\begin{array}{l}\text { Ability to synthesize highly } \\
\text { crystalline MIONPs in the } \\
\text { presence of surfactants }\end{array}$ & $\begin{array}{l}\text { High temperature is required } \\
\text { for producing nanopar- } \\
\text { ticles }\end{array}$ & 65 \\
\hline Hydrothermal & $\begin{array}{l}\text { 2-40 } \mathrm{nm} \text { with narrow distri- } \\
\text { bution }\end{array}$ & Spherical or cubic & $\begin{array}{l}\text { The particle size can be con- } \\
\text { trolled easily by regulating } \\
\text { the rate of nucleation and } \\
\text { grain growth }\end{array}$ & $\begin{array}{l}\text { High temperature and pres- } \\
\text { sure are required }\end{array}$ & $56-72$ \\
\hline
\end{tabular}


ahead, we briefly introduce some important synthetic methods of MIONPS suitable for biomedical and industrial interest. Comparison of various synthetic methods of MIONPs parameters apt for biomedical and industrial applications are given in Table 2.

\section{Co-precipitation method}

Co-precipitation is a simple and beneficial way to implement eco-friendly synthesis of MIONPs and it was first performed by Massart [28]. Figure 3 shows the preparation of $\mathrm{Fe}_{3} \mathrm{O}_{4}$ by using of ferrous and ferric salts in a molar ratio of $1: 2$ in alkaline aqueous solution under inert atmosphere at $70{ }^{\circ} \mathrm{C}$. The type of salts used (chlorides, sulfates, nitrates), $\mathrm{Fe}(\mathrm{II}) / \mathrm{Fe}(\mathrm{III})$ ratio, temperature, $\mathrm{pH}$ and ionic strength influence the size, shape and composition of the MIONPs. With standardized synthesis conditions, this process leads to the formation of spherical particles that allows mass production and do not require the use of expensive materials. The two main reasons that make the MIONPs derived from this method become widely applied in biomedical field are simple, consequential productivity and direct dispersion in water without further treatment. Despite the advantage of being fast, simple, economic, environment friendly and easily transposable on a large scale, this method results in polydispersed MIONPs and the process of controlling the particle size is laborious and time consuming [29].
Microemulsion and reverse microemulsion methods

Microemulsions act as nanoreactors to synthesise superparamagnetic nanoparticles using thermodynamically stable isotropic dispersion of two immiscible liquids and stabilized by a surfactant molecule [30]. This process allows the control of the particle radius by exploiting the size of the reactors and the quantity of precursors available in each emulsion [7]. Different anionic, cationic and neutral surfactants are used, such as sodium dioctylsulphosuccinate, cetyltrimethylammonium bromide [31], sodium dodecylsulphate and polyethoxylates (Tween) for significant effects [32]. These surfactants allow control over the particle size by limiting the phenomena of crystalline growth and agglomeration of the nanoparticles [7].

Figure 4 shows water-in-oil microemulsions where micro droplets of aqueous phase (below $50 \mathrm{~nm}$ ) are surrounded by a surfactant monolayer. In this method, two identical water-in-oil microemulsions containing the desired reactants were mixed to obtain the desired particle. By mixing both microemulsions, interchange reactants occurs by continuous collision, coalesce, break again and finally ends in the formation of precipitate within micelles. The precipitate can be extracted upon addition of ethanol or acetone to the microemulsions either by filtration or by centrifugation [25, 33]. Even though varieties of MIONPs (spheroids, tubes or oblong
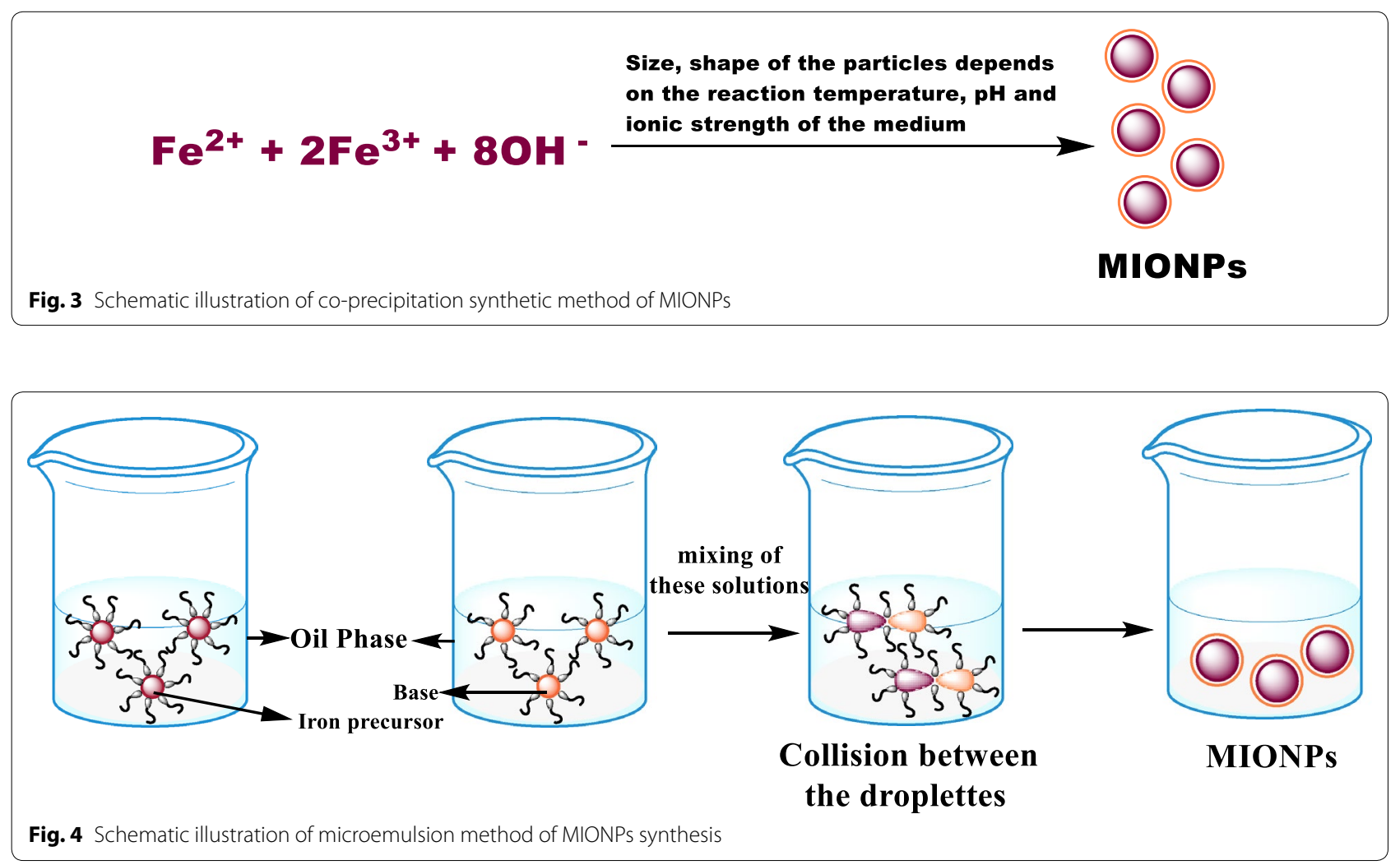
cross-sectioned nanoparticles) were synthesized by this method, yet it suffers from wide range of particle size and shape. In addition to that, this method offers low yield compared to co-precipitation $[25,33]$.

\section{Sonochemical method}

Decomposition of the iron precursors by thermolysis or sonolysis can also lead to the formation of iron oxide nanoparticles through sonochemistry. Organometallic precursors lead to amorphous, porous, agglomerated and small sized nanoparticles. The chemical effects of ultrasound arise from nonlinear acoustic phenomena, mainly acoustic cavitations such as the formation, growth and implosive collapse of bubbles in liquid [34]. Suslick et al. prepared nanoscopic amorphous iron powders using sonochemical methodology by taking iron carbonyl in decane [35]. These powders get fused and crystallized when heated above $300^{\circ} \mathrm{C}$. Figure 5 shows the sonication of iron carbonyl in the presence of a polyvinylpyrolidone (PVP) stabilizer which produces well-dispersed iron nanoparticles. Surfactants, namely octadecyltrichlorosilane and oleic acid, or synthetic and natural polymers namely polyvinyl alcohol and chitosan can be added during or after sonication. The hydrodynamic diameter of the coated spherical MIONPs was $15 \mathrm{~nm}$, ensuring the formation of good stable dispersion of nanoparticles [36, 37].

The very high temperature hot spot generated by the rapid collapse of sonically generated cavities allows for the conversion of ferrous penta carbonyl salts into MIONPs [8]. Ferrous acetate in deoxygenated water gives $10 \mathrm{~nm}$ sized $\mathrm{Fe}_{3} \mathrm{O}_{4}$ particles by this method. The main advantages of this method are the use of few reagents and lesser purification steps [38, 39]. However, a modern experimental setup is required. The particle size can be controlled by altering the metal precursor or by changing the temperature.

\section{Reduction or polyol method}

High-quality MIONPs are often synthesised by the reduction of different stable metal precursors such as oxides, nitrates, chlorides, acetates and acetyl acetonates in the presence of polyols as the medium. Polyols often function as reducing agent, solvent, stabilizing agents and to prevent interparticle aggregation [3, 40]. Figure 6 illustrates the polyol solution containing an iron precursor heated in the range of $210-220^{\circ} \mathrm{C}$, which in turn results in nucleation and growth. It subsequently decreased the rate of oxidation and easy dispersion in polar solvents [41]. Higher temperature favours monodispersed $\mathrm{Fe}_{3} \mathrm{O}_{4}$ nanoparticles with higher crystallinity and magnetization. The size and yield of MIONPs vary depending upon the type of polyols and ferrous salts, reduction potential of the polyols, ferrous and hydroxyl ion concentration and temperature. Polyols function not only as a solvent and a reducing agent, and also as a surfactant that limits agglomeration [34, 40, 41]. The benefit of this method is easy to control the experimental conditions and to scale-up.

\section{Thermal decomposition method}

The coprecipitation and sonochemical methods mentioned above have several intrinsic draw-backs which include difficulty in producing highly uniform sized MIONPs, relatively low degree of crystallinity [42]. Thermal decomposition is a popular method used in industries to synthesise narrow sized MIONPs. In this method, the precursor containing surfactant solution is injected into a solvent at high temperature which in

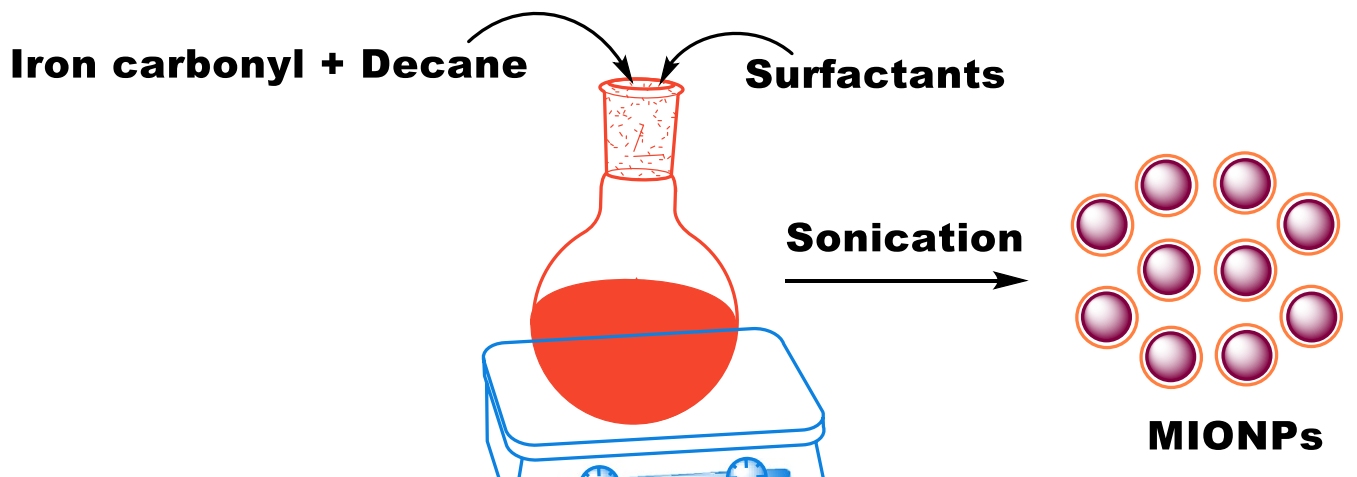

\section{High frequency sound waves (20 KHz to $10 \mathrm{MHz}$ )}

Fig. 5 Schematic representation of sonochemical synthesis of MIONPS 


\section{$\mathrm{FeCl}_{3}+\mathrm{FeCl}_{2}+\mathrm{Alkaline} \mathrm{medium} \mathrm{+} \mathrm{Ethylene} \mathrm{glycol}$

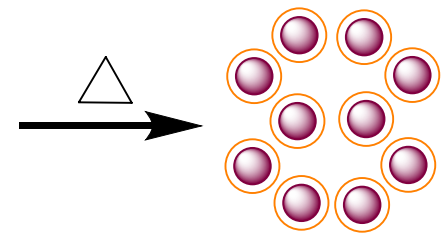 \\ MIONPs}

Fig. 6 Schematic illustration of polyol synthesis of MIONPs

turn decomposes the iron precursor in the presence of surfactant that will coat and stabilize the formation of MIONPs. By thermal decomposition method, highly mono dispersed MIONPs in a large scale can be synthesised using suitable iron precursors (iron acetylacetonate, iron cupferron, iron oleate and iron pentacarbonyl etc.)) in a hot surfactant solution [43]. For mass production of MIONPs, ferrous and ferric fatty acid complexes are mainly used due to its cost-effective, non-toxic and easy to scale up. The MIONPs synthesised by thermal decomposition method have high crystallinity with uniform size distribution led to the production of metallic nanocrystals and semiconductors.

\section{Hydrothermal method}

Hydrothermal synthesis of $\mathrm{Fe}_{3} \mathrm{O}_{4}$ nanoparticles in aqueous media are carried out in autoclaves/reactors at high temperature and pressure (above $200{ }^{\circ} \mathrm{C}$ and $13,790 \mathrm{kPa}$ ) [44-49]. Rapid nucleation and faster growth occurs at high temperature and it leads to formation of MIONPs (Fig. 7).

Two different routes were adopted for achieving MIONPs under hydrothermal conditions: (i) hydrolysis and oxidation and (ii) neutralization of mixed metal hydroxides [5]. The above two methods are similar, but differs in the use of pure ferrous salts in the former and the mixtures of ferrous and ferric salts in the later. This method makes it possible to control the geometry of the MIONPs by optimizing the conditions such as the reaction time, temperature, solvent, concentration and stoichiometry of reactants [45].

It was reported that the particle size of $\mathrm{Fe}_{3} \mathrm{O}_{4}$ was influenced by water content and reaction time. When the water content was higher it leads to formation of MIONPs of larger size. Reaction temperature is also one of the factors affecting the size of MIONPs. It was observed that the particle size of MIONPs is controlled through nucleation rate and grain growth. Higher temperature favours to rapid nucleation than grain growth and leads to formation of MIONPs of decreased size. The crystals formed by hydrothermal treatment are generally narrow sized with high purity and density. They do not aggregate due to the presence of stabilizing agents [4448]. Cai et al. synthesized polyethyleneimine (PEI) coated $\mathrm{Fe}_{3} \mathrm{O}_{4}$ nanoparticles via a one-pot hydrothermal method using PEI as stabilizer [46]. Li et al. discussed the recent advances in hydrothermal synthesis of MIONPs, the various aspects of the synthetic method and its functionalization for biomedical applications like MR or dual-mode MR/CT imaging applications in particular [48].

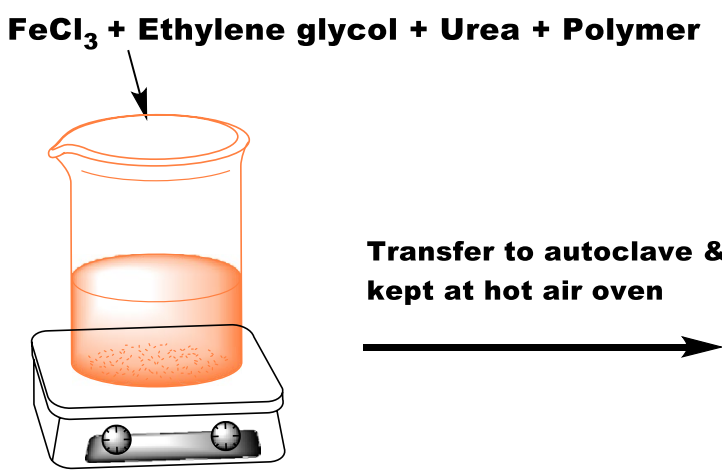

Fig. 7 Schematic illustration of hydrothermal synthesis of MIONPS

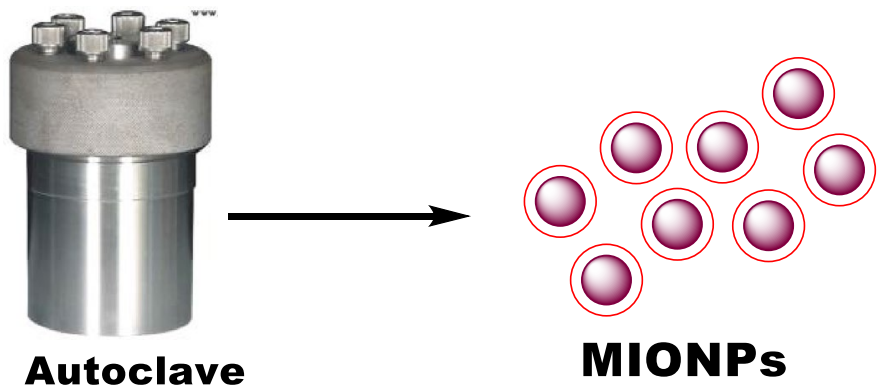




\section{Cytotoxicity}

Various studies indicate that a dose level of iron upto100 $\mu \mathrm{g} / \mathrm{mL}$ results in nontoxic effects. The toxicity is due to high dosage of iron. It is already known that iron, apart from its catalytic action is also involved in the generation of free radicals, which cause peroxidation of membrane lipids, nucleic acid modification and protein oxidation [50-52]. Cytotoxicity occurs in both in vitro and in vivo conditions. MIONPs offer a large surface area that contributes to the production of free radicals. In vivo toxicity is often caused by free radicals of MIONPs such as superoxide anion, nonradical hydrogen peroxide and hydroxyl radicals $[53,54]$.

MIONPs employed in biomedical applications such as targeted drug delivery to specific organs or tissues and usage of high concentration would consequently lead to its accumulation in the specific tissues or organs [55]. High levels of iron concentration in the tissues lead to imbalance in homeostasis causing undesired abnormal cellular responses such as oxidative stress, DNA damage and inflammatory responses which also induced carcinogenesis [56-60]. Excessive concentration of iron causes liver cancer, in particular. Nanoparticles have an impact on the cell's metabolic activity, proliferation, cell membrane integrity and apoptosis. Cytotoxicity of the nanoparticles is greatly minimized by appropriate choice of surface coating, size and shape of MIONPs. The nanoparticles can be spherical, rod-shaped, nanoworms and as magnetic beads. The extent of biocompatibility varies with different shapes and surface modifications [61]. The type of materials chosen for coating MIONPs and the products released upon their hydrolysis essentially determines their cytotoxic nature [62].

Surface coating of MIONPs with silica reduces its toxicity in live cells. Derivatives of dextran, polyethylene glycol (PEG), polyethyleneoxide (PEO), poloxamers and polyoxamines can also be used for surface coating. Nanoparticles coated with PEG decreases the chance of nonspecific uptake by macrophages [63]. Non-coated MIONPs carrying negative charge lead to protein denaturation when binding to serum proteins in the culture medium. There are also circumstances wherein vital nutrients and proteins required for cellular activities bind onto the non-coated MIONPs and severely affecting cellular activities like cell growth and viability [64]. Thus, surface coating aids in developing a hydrophilic nature in iron oxide nanoparticles implying better biocompatibility [65]. Without a doubt, cytotoxicity of MIONPs can be widely kept under control with appropriate surface modifications and coatings.

Most of the nanomaterials and wastes, which include nanoparticles and their by-products, will end-up in surface waters consequently enter into aquatic systems with unknown potential risks to biota. The properties which represent MIONPs useful for the environmental remediation, in particular their small size and high redox reactivity, the same make them potentially harmful to biota [54] where the adverse effects of nanoparticles in organisms remains unknown [2]. Chemical, physical, metabolic transformation and interaction with macromolecules will alter the fate, transport and toxicity of MIONPs [66]. Under natural conditions, while $\mathrm{Fe}^{0}$ is reduced faster to iron oxides/hydroxides, it can significantly minimize the risk to organisms due to less cytotoxicity [67]. Meanwhile, the degree and volume of corrosion product leads to increase in the size of MIONPs [68]. Surface modifications of MIONPs may influence physiochemical properties of NP and might increase risk to biota. It is always essential to investigate both the core and the coating materials in combination and independent of each other. On the laboratory scale, applications of MIONPs for remediation have already proved their efficiency [69]. Although effects of their end products and resultant byproducts have not been fully investigated, there is need of insight into the long-term functional studies, which includes persistency and migration of MIONP in environments [70].

\section{Surface modification and stabilization}

MIONPs synthesized by various methods require a surface modification to achieve biocompatibility and longstanding stability especially in biological media. MIONPs when left with a bare surface tend to agglomerate under the action of van der Waals forces, high surface energy and attractive magnetic forces existing among the particles. Stability and specificity are crucial for any application of MIONPs. Various natural and synthetic polymers, organic and inorganic materials are currently employed as stabilizing matrices. Figure 8 presents the various natural and synthetic polymer, organic and inorganic materials used for stabilization of MIONPs [21, 63, 71, 72]. Size and properties of surface modifying agents used to modify the MIONPs surface play a key. Small sized molecules favour uniform surface coverage. The challenge is to create a sufficiently strong repelling power within the nanoparticles and decrease the interfacial tension of the system in order to obtain stable particles [34]. It could be addressed by coating the particles with repelling hydrophobic surfactants. Ligand interchange and encapsulation methods with amphiphilic polymers have been engaged to produce water-dispersible and biocompatible MIONPs. Tables 3, 4 and 5 briefly shows the properties, structure and applications of important polymers, and inorganic materials used for the stabilization of MIONPS. 


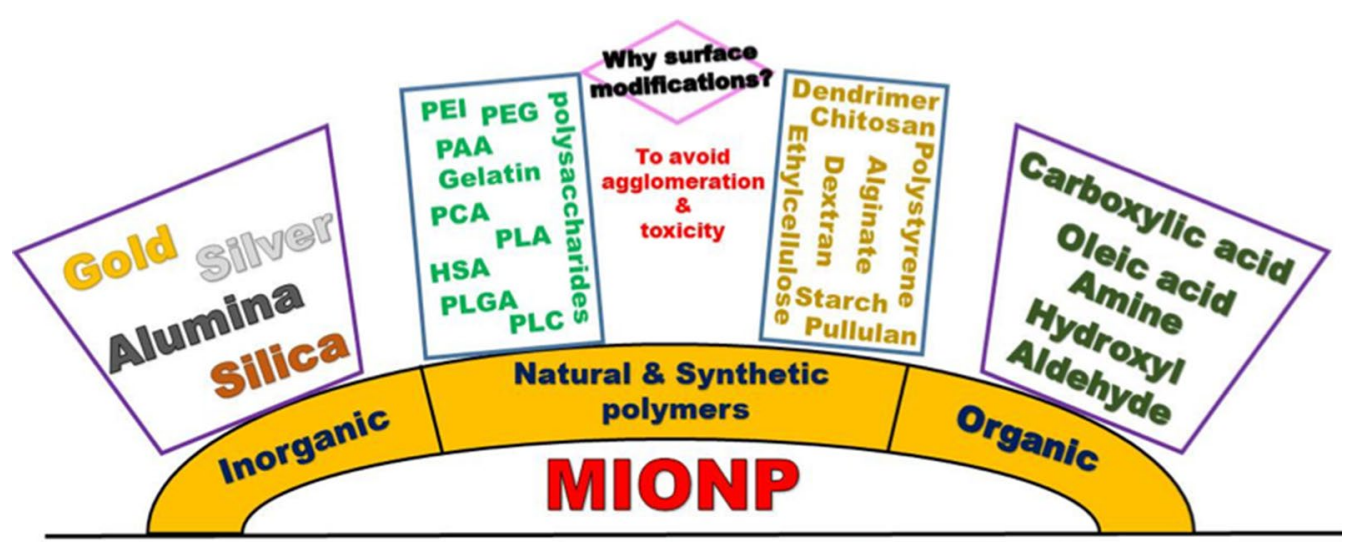

Fig. 8 Important surface modification materials for MIONPS

\section{Natural and synthetic polymers}

Electrostatic or steric repulsion can be used to prevent aggregation, disperse nanoparticles and preserve them in a steady colloidal state. The finest well-known example for such a system is the ferrofluid, invented by Papell in $1965[25,73]$. The most important measures to improvise the stability of ferrofluids are the regulation of surface charges by the use of specific polymers [25]. The polymeric shell can be manipulated with functional groups such as terminal amine or carboxyl moieties at the nanoparticle surface for further conjugation with bioactive molecules to target ligands and for other specific applications with multifunctional MIONPs [5].

A significant number of natural and synthetic biodegradable polymers are used (Tables 3 and 4), such as dextran [74], chitosan [75, 76], pullulan [77], human serum albumin [78], dendrimer [79, 80], polyaspartate [81], polysaccharides [82], gelatin [83], starch [84], alginate [85], polyethyleneimine [86, 87], poly(acrylic acid) [88], Polyethylene glycol [89], poly(D,L-lactide) (PLA) [90-92], PEG-poly(aspartic acid) [93], poly(PEG monomethacrylate) [94], PLA-PEG [95, 96], poly(D,L lactide-co-glycolide) (PLGA) [97, 98], poly(alkyl cyanoacrylate) (PACA) [99, 100], chitosan-L-glutamicacid [101], poly( $\varepsilon$-caprolactone) (PCL) $[102,103]$ and non-biodegradable polymers like ethylcellulose [104, 105] and polystyrene [106] for surface modifications. Surface modification of the particles with PEG is suitable for biomedical applications such as drug delivery due to its hydrophilic surfaces and prolonged rate of circulation in the blood stream. Surface coating with polystyrene on the other hand renders thermal sensitivity to the nanoparticles.

Table 3 Properties and applications of important natural polymers used to ensure stabilization of MIONPs

\begin{tabular}{|c|c|c|c|}
\hline Name & Nature and source & Characteristics & Applications \\
\hline Alginate & $\begin{array}{l}\text { Anionic polymer obtained from brown sea- } \\
\text { weed }\end{array}$ & $\begin{array}{l}\text { Biocompatible } \\
\text { Low cost and less toxicity } \\
\text { Addition of divalent cations result in mild } \\
\text { gelation leads to biomedical applica- } \\
\text { tions }\end{array}$ & $\begin{array}{l}\text { Used in } \\
\text { Delivery of low molecular weight drugs and } \\
\text { proteins } \\
\text { Wound dressing } \\
\text { Tissue and bone regeneration } \\
\text { Transplantation of stem cells }\end{array}$ \\
\hline Chitosan & $\begin{array}{l}\text { Cationic linear polymer derived from partial } \\
\text { deacetylation of chitin }\end{array}$ & $\begin{array}{l}\text { Biocompatible and biodegradable } \\
\text { Low allergenicity } \\
\text { Non-toxic }\end{array}$ & $\begin{array}{l}\text { Non-viral gene delivery system } \\
\text { Obesity and age-related disease treatment } \\
\text { Wound healing } \\
\text { Dry mouth syndrome treatment } \\
\text { Water treatment }\end{array}$ \\
\hline Dextran & $\begin{array}{l}\text { Water-soluble polysaccharide consists of } \\
\text { mainly a-1,6-glycosides and rarely with a-1,3 } \\
\text { branches obtained from bacteria }\end{array}$ & $\begin{array}{l}\text { Biocompatible and biodegradable } \\
\text { Optimum polar interactions } \\
\text { Low cost and simple alternation }\end{array}$ & $\begin{array}{l}\text { Colloidal solution is get stabilized by dextran } \\
\text { and also helps in increasing circulation } \\
\text { time in blood }\end{array}$ \\
\hline Pullulan & $\begin{array}{l}\text { Water-soluble polysaccharide comprising of } \\
\text { linear chains of D-glycopyranosyl units from } \\
\text { fungus Aureobasidium pullulans }\end{array}$ & $\begin{array}{l}\text { Adhesive ability } \\
\text { Boost nanoparticle colloidal stability } \\
\text { Accelerated biocompatibility }\end{array}$ & $\begin{array}{l}\text { Targeted drug delivery along with excellent } \\
\text { cytotoxic outcome } \\
\text { Transmucosal protein delivery }\end{array}$ \\
\hline
\end{tabular}


Table 4 Structure, properties and applications of important synthetic polymers used to stabilize MIONPs

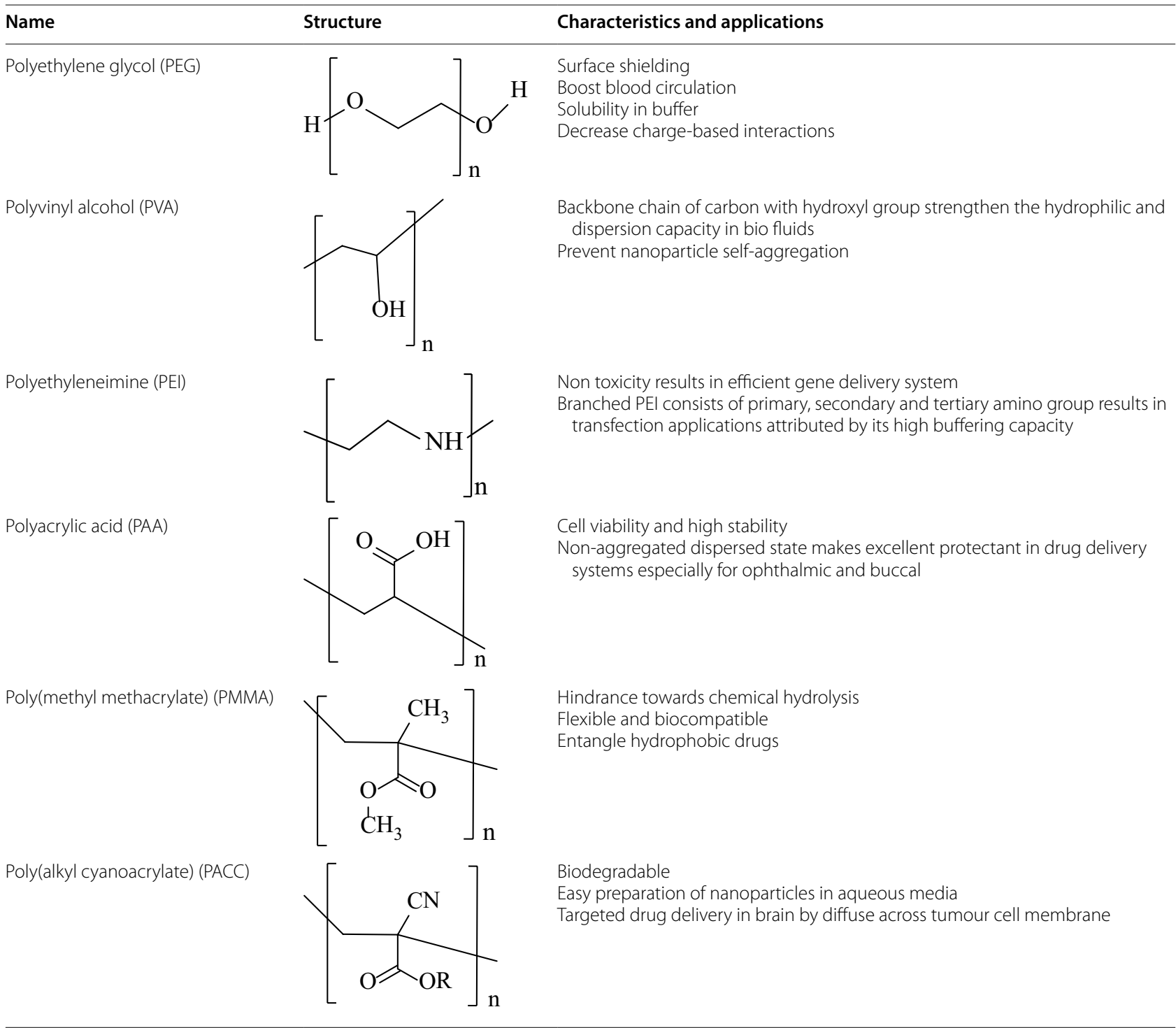

Table 5 List of important inorganic materials used to ensure stabilization of MIONPs

\begin{tabular}{ll}
\hline Matrices & Characteristics and applications \\
\hline Silica & Very stable and easily dispersed in solution \\
& Stable at wide range of pH \\
& Easy to attach several biomolecules, drug, fluorophores, quantum \\
dots, dyes and ligands & Inert and biocompatible \\
& Prevent aggregation of particles \\
Gold and silver & Protect MIONPs from low pH corrosion \\
& Offer extra optical properties \\
& Gold-silver chemistry facilitate easy conjugation with other molecules \\
& Several applications in drug delivery \\
\hline
\end{tabular}




\section{Organic materials}

Organic materials are often employed for the passivation of the nanoparticle surface, either during or after the synthetic procedure, to avoid agglomeration and the properties of organic molecules can be exploited for different applications. MIONPs with functionalized surface offer the basic magnetic characteristics along with retention of good biocompatibility and biodegradability. Their surface can be functionalized with reactive groups such as carboxyl, amine, hydroxyl, aldehyde that eventually can be used to bind to DNA and proteins such as antibodies, enzymes. Modifying MIONPs with dihexadecylphosphonic acid, dodecylphosphonic acid, hexadecylphosphonic acid, octadecanephosphonic acid, oleic acid, lauric acid, stearic acid, etc. can aid in stabilizing the nanoparticles in organic solvents [107-110]. Thermostability can be conferred to MIONPs by attaching alkyl phosphonates and phosphates.

\section{Inorganic materials}

Surface modifications on MIONPs are also accomplished with inorganic compounds. It significantly increases the anti-oxidant properties of naked MIONPs for wider application scope. The functional coating with inorganic materials like silica, metal, non-metal, metal oxides and sulfides enable their use in catalysis, bio-labelling and bio-separation. Modified composite MIONPs retain the properties of both the inorganic material and iron oxide magnetism.

Inorganic materials like silica [111], gold [112], alumina, also promotes stability in aqueous dispersion and offers a convenient platform for functionalization of the MIONPs for various applications. Chemical stability over broad $\mathrm{pH}$ range and biocompatibility is well achieved with silica coating to obtain stable ferrofluids.

Biomolecules and other such entities are crucial for targeted action and attachment of the desired moieties can be accomplished with ease by coating the particle surface with gold or silica. Silica outweighs other materials for coating the particles due to its silanol groups which in turn effectively reacts with coupling agents and offers classic support to suitable and desired molecules like proteins, ligands and antibodies on the surface via covalent bonding (Table 5). Jingchao Li et al. hydrothermally synthesized hyaluronic acid modified $\mathrm{Fe}_{3} \mathrm{O}_{4}-\mathrm{Au}$ nanoparticles for tri-mode (MR/CT/thermal) imaging and photothermal therapy for cancer. First, the synthesized $\mathrm{Fe}_{3} \mathrm{O}_{4}$ - $\mathrm{Ag}$ seeds are deposited with $\mathrm{Au}$ shells that can be modified with PEI via Au-S bond. Likewise, the PEI mediated reaction can be used for hyaluronic acid conjugation onto the surface of the nanoparticles [113]. Yong $\mathrm{Hu}$ et al. reported a unique multifunctional nanoplatform based on folic acid (FA) - modified $\mathrm{Fe}_{3} \mathrm{O}_{4}$ - $\mathrm{Au}$ nanoparticles. The PEI-coated $\mathrm{Fe}_{3} \mathrm{O}_{4}$ - $\mathrm{Au}$ nanoparticles were sequentially conjugated with FA through a polyethylene glycol (PEG) spacer via the PEI amine-enabled conjugation chemistry [114].

\section{Applications of MIONPs}

Nanometer sized MNPs are used in biomedical applications (Fig. 9) such as drug delivery, biosensors, biomolecular separation, purification and cell labelling due to their strong magnetic properties [115-123]. Addition of nano receptors to the surface aids in targeting the essential pharmacological agents to the specifically desired areas of the human body. These receptors are designed to specifically recognize the target tissues for binding and to consequently release the drug molecules.

MIONPs were preferably chosen for biomedical applications due to its convenient synthetic methods, low toxicity and high saturation magnetization [124]. Surface modifications of MIONPs are mandatory requirements that are heteronomous on the type of NP core and the aspired applications. Non-coated iron oxide NPs will have different effects on the cells of the body. Conjugation of biomolecules on the surface of nanoparticles is made possible via hydrogen, covalent, or ionic bonds. Surface modifications have an impact on its magnetization, particle size, solubility and agglomeration in different solvents. Surface modification aims in attaining hydrophilic, hydrophobic, conductive and anti-corrosive properties in the NP. Widely used nano materials for surface coating are $\mathrm{SiO}_{2}, \mathrm{TiO}_{2}, \mathrm{Al}_{2} \mathrm{O}_{3}, \mathrm{Fe}_{2} \mathrm{O}_{3}$, nano-aluminium, nano-titanium. MNPs are exploited for theragnostic applications inclusive of visualization of the desired bio species, guiding into preferred sites using a magnetic field and heating in order to trigger drug release or to produce hyperthermia of desired tissues [12, 122-125].

\section{Bio-sensing}

Nanomaterials have an appeal for being used as biosensors due to their high catalytic efficiency, adsorption ability, large surface-to-volume ratio for surface reaction and for the ease of immobilizing suitable molecules for bio-sensing such as for glucose detection. MIONPs can be used as a biosensor for its stable catalytic activity toward several substrates of biological or environmental consequence, such as soluble oxygen, trichloroacetic acid, nitrite and hydrogen peroxide [126]. The principle behind the detection involves the oxidation of glucose by glucose oxidase to yield peroxide which further oxidises ABTS (2,2'-azino-bis(3-ethylbenzothiazoline-6-sulphonic acid)) in the presence of peroxidase. This chromogenic reaction aids in detecting glucose. The release of hydrogen peroxide during glucose oxidation is used to indirectly detect glucose. 


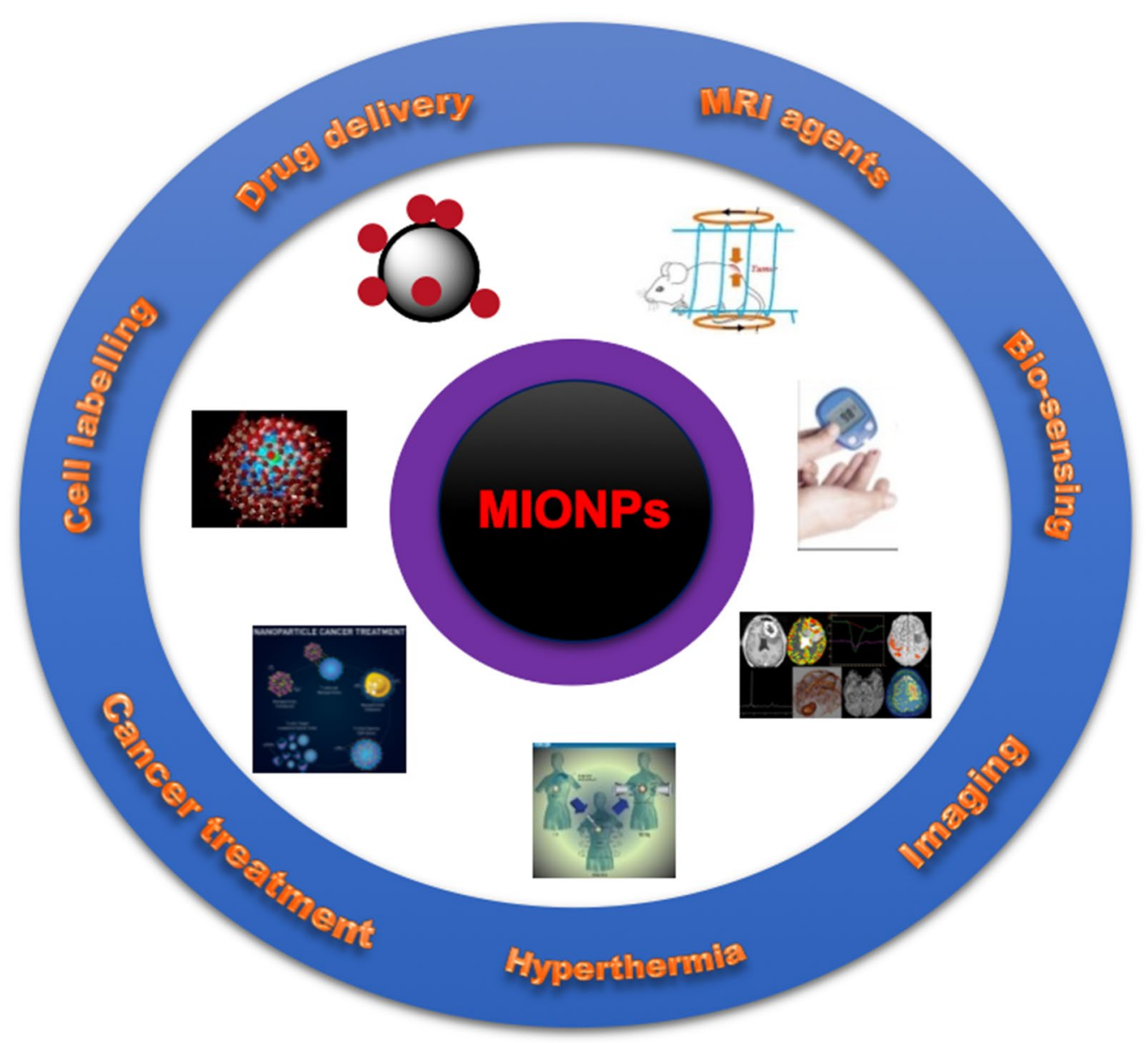

Fig. 9 Important biomedical applications of MIONPS

MIONPs were found to have the functions of peroxidise when they were attached with horseradish peroxidase [127]. Large scale production of peroxidase enzymes are hard due to the possibilities of proteolytic degradation whereas such problems are not encountered for yielding higher mass of MIONPs. The choice of MIONPs for immobilizing glucose oxidase is attributed to its low toxicity, superparamagnetic nature and biocompatibility along with prolonged stability [126, 128]. MIONPs are appreciated for bio-sensing due to its high sensitivity and rapid result. An essential aspect of its catalytic ability depends on its binding with the substrate. Binding affinity with the substrate can be regulated by manipulating the charge and its strength on the surface of MIONPs. This can be achieved by using different surface-active materials. Various surface modifications with citrate and g lycine, polylysine and poly(ethyleneimine) or carboxymethyl dextran and heparin could be done for glucose detection.

\section{Drug delivery}

Nanoparticles are being preferred in the drug delivery action due to their efficiency in targeting drugs to the desired diseased cells and tissues [129, 130]. The nanoparticle surface contains a ligand along with the polymer coating which binds with the specific receptor on the target. The entry of drug loaded nanoparticles into the aspired destination highly depends on the ligandreceptor match. The nanoparticles are denied entry into the cell when the ligand-receptor match fails. When this comes to treating diseases, it has the additional advantage of prolonging the existence of drugs inside the biological system with parallel benefits of decreasing the frequency of painful injections. 
MIONPs are attributed for their distinctive characteristics and potential to perform at the cellular level with high specificity and low toxicity [131]. The toxicity is further reduced by concealing the drugs within the designed nanocarrier [127, 132]. Other prospective advantages include the achievement of desired drug concentration at the target site with low quantity of loaded drug on the carrier and reduced concentration of drug at the non-target sites $[125,133]$. Drugs can be combined with MIONPs in several ways. They could be accumulated on the MIONP surface or trapped within the MIONP structure. They could also be attached with the functionalised moieties on the MIONP surface. Drugs are liberated at the target site by diffusion, dissolution, endocytosis [134, 135].

\section{Cancer treatment}

Chemotherapeutic strategies to treat cancer are mostly non-specific and leads to the destruction of many healthy cells along with the target tumour. MIONPs could be used as specific drug carriers to outstand such problems [136]. Various chemotherapeutic drugs like methotrexate (MTX), doxorubicin (DOX), paclitaxel are conjugated with MIONPs to fight cancer [137-139]. Yu et al. synthesised MIONPs coated with a negatively charged polymer to load the positively charged doxorubicin (DOX) with electrostatic interactions [140]. These MIONPs demonstrated reduction in the tumour size when injected into mice with lung cancer. MIONPs can be used to treat cancer in various ways [141].

MIONPs are conjugated with monoclonal antibodies in cancer treatment. Cancer cells are distinguished from normal cells with increased number of epidermal growth factor receptors (EGFR) which actively binds to epidermal growth factors. These growth factors induce the ability of the cancer cells to increase in size, volume and promote cellular division. Monoclonal antibodies bind specifically to epidermal growth factor receptors blocking them to prevent their binding to EGF.

Hyperthermia for tumour therapy can be achieved with MIONPs. The effect of hyperthermia is produced when MIONPs act as an oscillating magnet under external magnetic field followed by its conversion into heat to raise the temperature of tumour tissues and subsequent destruction of pathological cells. Specific absorption rate (SAR) determines the heat attained by the MIONPs. SAR defines the conversion of magnetic field to heat. SAR values for MIONPs are generally estimated with Neel and Brownian relaxation. Tumour cells are made inviable by exposing them to a temperature range of $41-45{ }^{\circ} \mathrm{C}$ for a time span of $30 \mathrm{~min}$. Heat produced in the treatment is restricted to the specific tumour tissues pertaining to the property of MIONPs where heat is produced at the cost of hysteresis loss on exposure to high frequency of approximately $1 \mathrm{MHz}$.

MIONPs can be loaded with drugs and are guided to the desired target site with an external magnetic field with simultaneous tracking and bio distribution of nanoparticles proving them theragnostic [142]. MIONPs existing in conjugation with the required targeting moieties fused with the application of an external magnetic field assure a very promising alternative for simultaneous imaging of inflammation and drug delivery to inflammatory sites by maintaining an appropriate local concentration with reduced overall dosage and side effects [12, 143].

MIONPs can be manifested to carry specific drugs for the therapy. The choice of using MIONPs for delivering drugs within the human body is to increase the drug life and its protection from degradation by specific surface modification of nanoparticles [144]. The extremely small sizes of MIONP succour them to penetrate through smaller capillaries and hence are captured by affected cells with ease. The drug employed for therapeutic purpose can either be active or passive. Active drugs are targeted to the explicit sites of the system like tissues, organs, cells. Passive drugs are circulated throughout the biological system homogenously. These methods of drug circulation are implemented and favoured by the properties of the drug's carrier. Circulation and distribution of drugs are efficiently controlled by external magnetic field. MNPs prove itself very efficient with their ability to cross various biological barriers like the blood brain barrier (BBB) and penetrate deep inside. MIONPs make it possible to efficiently deliver drugs to the brain tumour cells. MIONPs in the gene delivery system loads the therapeutic genes for escorting them to the diseased sites to facilitate their shuttling across the target cell membranes and to ultimately release them intracellularly to accomplish their functions [142, 145, 146].

The sizes of MIONPs play a very crucial role in its biological elimination within the body. Particles with sizes more than $200 \mathrm{~nm}$ are usually filtered in the spleen. MIONPs around $100 \mathrm{~nm}$ are predominantly phagocytosed by liver cells and hence MIONPs with large size have a short life period in the plasma [125]. The potency of this method highly depends on field strength, blood flow rate, thickness of tissues at the target site, etc. [147]. Small MIONPs remains in blood plasma evading the biological elimination and their superparamagnetic nature prevents agglomeration in the absence of external magnetic field [148]. The physical and chemical properties of MIONPs can be enhanced for utilization by additional 
functionalization's with amino group, various surfactants, polymer, silica or other organic compounds. The functional groups existing on the surface coated polymer has the advantage to attain new properties or to enhance the existing properties of drugs.

\section{Imaging}

MIONPs also led its way in magnetic resonance imaging (MRI) owing to quantitative data with superior spatial resolution and appreciable penetration into tissues despite being harmless of the magnetic field [121, 149-153]. The human body has a net magnetic moment of zero and exhibits a significant magnetic moment with the presence of an external magnetic field. MRI is done 40 min after infusing MIONPs. MIONPs are later eliminated from the system by immune cells through phagoctosis. MIONPs offer benefits like safety, high relaxivity and blood half-life. Vascular structures like cardiac chambers, pulmonary arteries and aorta can be imaged with MRI. Thus, nanoparticles hold significant potential both for MRI and MRI-guided delivery (i.e., controlled drug or gene delivery) [121, 152, 153].

\section{MIONPs for tumour imaging}

The over expressed ligands on the surface of tumour cells serve as the target for imaging. $\alpha_{\mathrm{v}} \beta_{3}$ integrin is found on the surface of many tumours in breast cancer, prostate cancer, ovarian cancer, glioblastoma, etc. $\alpha_{v} \beta_{3}$ integrin plays an important role in metastasization and angiogenesis. A cyclic arginine-glycine-aspartic acid (cRGD) peptide sequences are designed to target integrin's [154-156]. MIONPs were functionalised with phosphonate PEG chains covalently linked with cRGD peptide sequence. These MIONPs were tested in vivo in tumour xenograft mice to check their efficacy in functioning as a contrast agent. MIONPs accumulated at the tumour sites after injection showed efficient and specific targeting of the tumour cells. MIONPs synthesised with $\mathrm{Si}-\mathrm{OH}$ containing co-polymer for the surface could also be used as a contrast agent for in vivo imaging of cancer cells.

\section{MIONPs in MRI for stem cell tracking}

Stem cells are undifferentiated mass of cells that have the marvellous potential of differentiating into different cell types. Their important properties are self-renewal and differentiation potential. Self-renewal results in the cell divisions to form daughter cells and the daughter cells mature into various types of cells with its capacity to differentiate. Sometimes loss of control over the proliferation of embryonic stem cells may lead to tumour formation with inconsistent phenotype. MIONPs can be used to track these stem cells with the widely adopted existing imaging technique-MRI. Interaction of MIONPs with stem cells are very much dependent on cell receptors, antibodies and the charge of cell membrane. Hence MIONP architecture combined with complementary target proteins, ligands have gained desirability over the past few decades in medical applications [157-160]. MIONPs can either be conjugated to the surface of stem cells or could be internalised [161]. Surface architecture and the size are altered to boost successful cellular uptake of MIONPs for non-invasive tracking of stem cells. MIONPs with low iron content favours by its low toxicity and the release of iron during its breakdown has been studied to have insignificant toxicity and it's the surface coating material that largely influences the cell. Cellular uptake of MIONP can be enhanced by the use of suitable polymer coating, transfection agents or by linking the MIONP with monoclonal antibodies [162-166].

\section{MIONPs for brain tumour}

Glioblastoma is a brain tumour that is hard to treat despite early detection due to its infiltrative nature causing recurring tumours in the diseased patients [167]. Current treatment including surgery, radiation and adjuvant chemotherapy leaves residual tumour cells in the patients which eventually lead to their death $[168,169]$. MIONPs can be used to image tumours via MRI by conjugating specific antibodies or peptides to target cancer cells $[170,171]$. Blood brain barrier poses a major challenge to this treatment strategy. Intratumoural delivery of MIONPs favours its desired concentration at the tumour target with low toxicity and maximum hyperthermic effect in the tumours alone rather subjecting the entire brain to hyperthermia. Exposure of healthy tissues to hyperthermia leads to various side effects [172]. Brain autopsies have confirmed the presence of MIONPs within tumour targets after implantation [173].

\section{Oil recovery}

Oil spills are generally caused by damaged tankers, destruction of oil pipelines, etc. It results in huge economic lose and environmental damage that usually lasts for a span of several decades. Oil spills have a wide negative impact on birds, mammals, fishes and to the ecosystem. The oil is found adsorbed on the rocks and the sand which offers unfavourable conditions for plant growth. The oil floating over the water destroys the underwater ecosystem and disrupts food chain. Birds and animals tend to ingest the oil which is poisonous to them. Even a small amount of oil is detrimental to birds. Oil stuck to the feathers of the birds hinders their flight and causes hypothermia. Adult fishes on exposure to oil suffer from altered respiration rates, fin erosion, enlarged liver and impaired reproductivity. The oil clogs the blowholes 
of dolphins and whales causing hindrance for them to breathe and communicate. Oil spills are generally sequestered with floating barricades and are then removed through vacuum or by special absorbents [174]. Current treatment strategies have their share of limitations that includes low efficiency, high labour and toxicity, sinking of oil and the consequent damage to the marine eco-system. Novel strategies are developed for oil recovery using nanotechnology for their higher efficiency in oil removal over a shot span of time and cost effectiveness $[175,176]$. MIONPS coated with polysiloxance and collagen help in efficient oil recovery $[177,178]$. Calcagnile et al. discovered that MIONP bound to polyurethane foam make oil separation possible with efficient recovery and reusability [179]. Various studies have highlighted the prospective role of MIONPs in oil recovery. Due to its low toxicity and easy magnetic separation, MIONPs appears to be more functionally efficient than cobalt or nickel nanoparticles $[25,180]$. MIONPs coated with superhydrophobic polyester material displayed selective adsorption of oil [181]. MIONPs functionalised with hydrothermally reduced graphene oxide ( $\mathrm{RGO}$ ) foam are used for oil adsorption and it could be easily separated with magnetic field. RGO foam is attributed as a fantastic sorbent for oil recovery due to its hydrophobicity, high surface area and easy recovery. It demonstrated a sorption capacity of $40 \mathrm{~g}$ oil/g foam [182]. Silicate clay could also be used to coat MIONP for enhancing oil spill treatments [183]. MIONPs synthesised with amphiphilic organic domains on their surface could be used for seizing hydrocarbons in the crude oil. The contaminants were removed at a ratio of $10 \mathrm{mg}$ of oil per $1 \mathrm{mg}$ of MIONPs and the MIONPs were withdrawn by external magnetic field. Zhu et al. demonstrated that MIONPs coated with vinyl triethoxysilane manifests efficient oil sorption [177]. These materials showed selective adsorption to hydrophobic pollutants in the contaminated environment. Amphiphilic materials have the advantage of recovering oil with different densities [184]. Mesoporous silica-coated MIONPs are an amphiphilic recovery agent that has shown high adsorption efficiency of hydrocarbons in the polluted aqueous environment. The hydrophobic MIONPs could be made oil-adsorbing by coating the particles with polytetrafluoroethylene through particle deposition technique. It resulted in low cost rapid oil adsorption, good magnetic response and the particles floated on water due to their low weight enabling easy removal. The synthesis and reusability need to be focused to incorporate more novelty to this strategy [185].

\section{Catalysis}

MIONPs are preferred over other metal catalysts for their non-toxic, ubiquitous and cost effectiveness. They have indeed become increasingly appealing in the field of catalysis over the last decade as they combine their fascinatingly reactive properties with an easy environmental benign mode of recovery [186]. The separation of MIONPs indulges them in the prominent industrial applications [187]. It could be used bare [188, 189] or by plating it with an appropriate metal that is catalytically active [190, 191]. MIONPs are well renowned for its easy recovery, ease of handling and catalytic activity for various applications. MIONPs can be used as a catalyst for anti-Markovnikov conversion of alkenes to alkynes by the addition of thiols. It could also be used as a catalyst for thia-Michael addition, substitution reaction and thiol esters synthesis. The addition reaction of thiophenol with styrene in the presence of $4 \mathrm{~mol} \%$ MIONPs as catalysts resulted in anti-Markovnikov products with a yield range of $95-100 \%$. MIONPs have the catalytic ability to alter the rate of the reaction in an anti-Markovnikov fashion and the catalytic activity was found to be restored for eight successive runs after followed by repeated washing. No major alterations in the morphology or distortions in the structure were observed due to repeated washing and hence it serves as an effective catalyst [192-196].

MIONPs synthesised in situ between the reaction of hydrazine monohydrate and iron salt in methanol at high temperature have proved to be effective catalysts in specifically reducing aromatic nitro groups into anilines with the aid of a reducing agent like hydrazine [197]. MIONPs have also involved in methylene blue degradation. Methylene blue degradation accomplished by sodium borohydride was found to have an escalated rate of degradation reaction after the addition of MIONPs [198].

\section{Water remediation}

Water being one of the most imperative entities needs to be remediated and preserved for beneficial global sake. There are beneficial elements in water which when exceeds in concentration can be extremely toxic. Higher concentration of fluoride intake will cause fluorosis. This chronic condition can be prevented by defluoridation. MIONPs coated with hydrotalcite or chitosan [199] has been discovered to withdraw high amounts of fluoride from drinking water via ion exchange mechanisms and electrostatic adsorption where the negatively charged fluoride gets attracted to the positively charged aluminium, magnesium and ferric ions on the surface of the nanoparticle. Studies revealed that large amount of fluoride were adsorbed at acidic conditions whereas MIONPs were able to remove the least amount of fluoride at alkaline conditions. So desorption of the adsorbed fluoride 
on MIONPs are usually removed in alkaline conditions. They can also be used to specifically eliminate trace elements to regulate remediation [19]. MIONPs synthesised by the reduction of borohydride or polyphenol with $\mathrm{Pd}$ and $\mathrm{Ni}$ fabrication have been successful in rapid and efficient reduction of unwanted pollutants [199-201]. Polychlorinated biphenyls (PCBs) can be removed from ground water using polyvinylidene fluoride (PVDF) membrane functionalised with polyacrylic acid (PAA) coated MIONPs. PCBs are removed by combined oxidative and reductive degradation [202]. In the case of selenium, selenium is reduced to selenate (VI), and selenite (IV) to elemental selenium and selenide by MIONPs [200, 203, 204]. Arsenic richly found in sediments and rocks are highly likely to be found in drinking water and its consumption deteriorates living beings. MIONPs integrated with different materials have shown large potential in removing heavy and toxic metals from drinking water [19, 205-207].

\section{Conclusions and perspectives}

As the perspective of the implication of MIONPs in biomedical and industrial research has been increasingly witnessed, the main motive is to enlighten the efficient MIONP synthetic methods with minimal hazards, at the same time to alleviate the efficacy issues of MIONPs owing to their cytotoxicity. Such cytotoxic effects can be subsided and kept under control through proper surface modifications, using polymers, silica coating and several other available functionalization strategies discussed earlier. MIONPs are eco-friendly and represent a higher performance than other types of nanoparticles due to their chemical stability and biocompatibility with costeffectiveness. Unlike the MIONPs, the cobalt and nickel nanoparticles are susceptible to oxidation, as they exhibit toxicity towards biological entities, and therefore not suitable for biomedical applications.

Silica coating, apart from being an efficient surface modification tool which reduces toxicity by minimising particle aggregation also provides stability and aids biocompatibility. Bigger particles possess the added advantage of their ease in separation, despite their limitations such as low magnetic moment and particle aggregation. On the other hand, small sized particles have a higher magnetic moment and aggregate less, however posing problems on their separation thus complicating the entire process. In order to strike a balance between these two approaches, incorporation of small sized MIONPs into clusters seem to be the most efficient way for increasing the magnetic moments per carrier together with easy separation.

In the current research scenario, nanoparticles are the preferred candidates for drug delivery action due to their efficiency in targeting drugs to the diseased cells and tissues. It can be advanced one step further by coupling various moieties responsive to suitable external stimuli such as temperature, light, etc. to improve the efficiency of targeted drug delivery and to allow programmed delivery of therapeutic agents. In order to attain uniform particles with desired charge, shape, size and magnetic moment, more efforts can be emphasised on optimizing the synthetic methods. The efforts through this review also clearly paves a way for the efficient synthesis of MNPs, to overcome the several obstacles discussed hitherto. It provides further hints to exploit efficient synthetic methods, while keeping in mind the vital scope of MIONPs for biological and industrial applications.

\section{Abbreviations}

BBB: blood brain barrier; CGPC: chitosan-L-glutamicacid, poly( $\varepsilon$-caprolactone); CRGD: cyclic arginine-glycine-aspartic acid; CT: computer tomography; FA: folic acid; $\mathrm{Fe}_{3} \mathrm{O}_{4}$ : magnetite; MIONPs: magnetic iron oxide nanoparticles; MNPs: magnetic nanoparticles; MRI: magnetic resonance imaging; PAA: polyacrylic acid; PACA: poly(alkyl cyanoacrylate); PCB: polychlorinated biphenyls; PEG: polyethylene glycol; PEl: polyethyleneimine; PLA: poly(D,L-lactide); PLA-PEG: poly-D,L-lactide-co-polyethylene glycol; PLGA: poly(D,L-lactide-co-glycolide); PMMA: poly(methyl methacrylate); PVDF: polyvinylidene fluoride; PVP: polyvinylpyrrolidone; PVA: polyvinyl alcohol; SAR: specific absorption rate; $\gamma-\mathrm{Fe}_{2} \mathrm{O}_{3}$ : maghemite; $\mathrm{a}-\mathrm{Fe}_{2} \mathrm{O}_{3}$ : hematite.

\section{Acknowledgements}

This work was supported by Department of Science and Technology Nanomission, Government of India [Grant No. DST/NM/NB-2018/10(G)], Science and Engineering Research Board, Department of Science and Technology, India [Grant No. YSS/2014/00026] and University Grants Commission, India [Grant No. F. 4-5(24-FRP)/2013(BSR)]. This article is a result of the project NORTE-010145-FEDER-000012, supported by Norte Portugal Regional Operational Programme (NORTE 2020), under the PORTUGAL 2020 Partnership Agreement, through the European Regional Development Fund (ERDF). This work was also financed by FEDER-Fundo Europeu de Desenvolvimento Regional funds through the COMPETE 2020-Operacional Programme for Competitiveness and Internationalisation (POCI), Portugal 2020, and by Portuguese funds through FCT-Fundação para a Ciência e a Tecnologia/Ministério da Ciência, Tecnologia e Ensino Superior in the framework of the project "Institute for Research and Innovation in Health Sciences" (POCI-01-0145-FEDER-007274).

\section{Authors' contributions}

VT conceived of the paper. BS, MT and VT participated in discussions of views represented in the paper. SN, KH, GP, BS, MT and VT wrote the review. All authors read and approved the final manuscript.

\section{Funding}

The funding from the Department of Science and Technology Nanomission, Government of India [Grant No. DST/NM/NB-2018/10(G)], Science and Engineering Research Board, Department of Science and Technology, India [Grant No. YSS/2014/00026] were responsible for the access to bibliographic information for this review paper. University Grants Commission, India [Grant No. F. 4-5(24-FRP)/2013(BSR) and UGC-RFSMS] is responsible for the salaries of $\mathrm{VT}$ and SN.

The funding from the project NORTE-01-0145-FEDER-000012, supported by Norte Portugal Regional Operational Programme (NORTE 2020), under the PORTUGAL 2020 Partnership Agreement, through the European Regional Development Fund (ERDF) and COMPETE 2020-Operacional Programme for Competitiveness and Internationalisation (POCI), Portugal 2020, and by Portuguese funds through FCT-Fundação para a Ciência e a Tecnologia/Ministério da Ciência, Tecnologia e Ensino Superior in the framework of the project "Institute for Research and Innovation in Health Sciences" 
(POCl-01-0145-FEDER-007274) were responsible for the salary of BS and access to bibliographic information for this review paper.

\section{Availability of supporting data}

The availability of data and materials is available online in references, as this is a review manuscript.

\section{Competing interests}

The authors declare that they have no competing interests.

\section{Author details}

${ }^{1}$ Photonics and Biophotonics Lab, School of Chemistry, Bharathidasan University, Tiruchirappalli 620 024, India. ${ }^{2}$ School of Biotechnology and Genetic Engineering, Bharathidasan University, Tiruchirappalli 620024 India. ${ }^{3}$ Kamakshi Educational Research Services, Hyderabad 500 079, India. ${ }^{4}$ INEB-Instituto de Engenharia Biomédica, University of Porto, Rua Alfredo Allen 208, 4200-135 Porto, Portugal. ${ }^{5}$ i3S-Instituto de Investigação e Inovação em Saúde, Universidade do Porto, Rua Alfredo Allen 208, 4200-135 Porto, Portugal. ${ }^{6}$ CESPU, Instituto de Investigação e Formação Avançada em Ciências e Tecnologias da Saúde \& Instituto Universitário de Ciências da Saúde, Rua Central de Gandra 1317, 4585-116 Gandra, Portugal. ${ }^{7}$ School of Pharmacy, Queen's University Belfast, Medical Biology Centre, 97 Lisburn Road, Belfast BT9 7BL, UK. ${ }^{8}$ Department of Biomedical Sciences and Medicine (DCBM), Centre for Biomedical Research (CBMR), University of Algarve, Campus de Gambelas, 8005-139 Faro, Portugal.

Received: 21 May 2019 Accepted: 24 October 2019 Published online: 19 November 2019

\section{References}

1. Zhu K, Ju Y, Xu J, Yang Z, Gao S, Hou Y. Magnetic nanomaterials: chemical design, synthesis and potential applications. Acc Chem Res. 2018;51:404-13.

2. Boris IK, Rasika Dias HV, Oxana VK, Victor Manuel JP, Betsabee OP, Blanca MF. Iron-containing nanomaterials: synthesis, properties, and environmental applications. RSC Adv. 2012;2:9325-58.

3. Daishun L, Taeghwan H. Chemical design of biocompatible iron oxide nanoparticles for medical applications. Small. 2013;9:1450-66.

4. Lyshevski SE. Dekker encyclopedia of nanoscience and nanotechnology. 3rd ed. Boca Raton: CRC Press; 2014. p. 7.

5. Harivardhan Reddy L, Arias JL, Nicolas J, Couvreur P. Magnetic nanoparticles: design and characterization, toxicity and biocompatibility, pharmaceutical and biomedical applications. Chem Rev. 2012;112:5818-78.

6. Ulbrich K, Holá K, Subr V, Bakandritsos A, Tucek J, Zboril R. Targeted drug delivery with polymers and magnetic nanoparticles: covalent and noncovalent approaches, release control, and clinical studies. Chem Rev. 2016;116:5338-431.

7. Laurent S, Vander Elst L, Muller RN. Superparamagnetic iron oxide nanoparticles for MRI. In: The chemistry of contrast agents in medical magnetic resonance imaging, Chapter 10. 2013. p. 427-47.

8. Laurent S, Forge D, Port M, Roch A, Robic C, Vander Elst L, Muller RN. Magnetic iron oxide nanoparticles: synthesis, stabilization, vectorization, physicochemical characterizations, and biological applications. Chem Rev. 2008;108:2064-110.

9. Shokrollahi H. Structure, synthetic methods, magnetic properties and biomedical applications of ferrofluids. Mater Sci Eng C. 2013;33:2476-87.

10. Ali A, Hira Zafar MZ, ul Haq I, Phull AR, Ali JS, Hussain A. Synthesis, characterization, applications, and challenges of iron oxide nanoparticles. Nanotechnol Sci Appl. 2016;9:49-67.

11. Amtenbrink MH, Von Rechenberg B, Hofmann H. Nanostructured materials for biomedical applications, Chapter 5. Trivandrum: Transworld Research Network; 2009. p. 119-49.

12. Mahmoudi M, Sahraian MA, Shokrgozar MA, Laurent S. Superparamagnetic iron oxide nanoparticles: promises for diagnosis and treatment of multiple sclerosis. ACS Chem Neurosci. 2011:2:118-40.

13. Colombo M, Carregal Romero S, Casula MF, Gutierrez L, Morales MP, Bohm IB, Heverhagen JT, Prosperi D, Parak WJ. Biological applications of magnetic nanoparticles. Chem Soc Rev. 2012;41:4306-34.
14. Rosi NL, Mirkin CA. Nanostructures in biodiagnostics. Chem Rev. 2005;105:1547-62.

15. Gautam A, Van Veggel FCJM. Synthesis of nanoparticles, their biocompatibility and toxicity behavior for biomedical applications. J Mater Chem B. 2013;1:5186-200.

16. Wegmann M, Scharr M. Synthesis of magnetic iron oxide nanoparticles. In: Precision medicine tools and quantitative approaches. 2018. p. 145-81.

17. Berry CC, Curtis ASG. Functionalisation of magnetic nanoparticles for applications in biomedicine. J Phys D Appl Phys. 2003;36:198-206.

18. Jiles DC. Introduction to magnetism and magnetic materials. 2nd ed. London: Chapman and Hall; 1991.

19. Gutierrez AM, Dziubla TD, Hilt JZ. Recent advances on iron oxide magnetic nanoparticles as sorbents of organic pollutants in water and wastewater treatment. Rev Environ Health. 2017;32:111-7.

20. Cornell RM, Schwertmann U. The iron oxides: structures, properties, reactions, occurences and uses. Weinheim: Wiley-VCH; 2003.

21. Wei W, Zhaohui W, Taekyung Y, Jiang C, Kim W. Recent progress on mag netic iron oxide nanoparticles: synthesis, surface functional strategies and biomedical applications. Sci Technol Adv Mater. 2015;16:023501.

22. Moaca E-A, Coricovac ED, Soica CM, Pinzaru IA, Pacurariu CS, Dehelean CA. Preclinical aspects on magnetic iron oxide nanoparticles and their interventions as anticancer agents: enucleation, apoptosis and other mechanism. Iron Ores Iron Oxide Mater. 2018:229-54.

23. Teja SA, Koh PY. Synthesis, properties, and applications of magnetic iron oxide nanoparticles. Prog Cryst Growth Charact. 2009;55:22-45.

24. Cullity BD. Introduction to magnetic materials. 2nd ed. Boston: Addison-Wesley Pub. Co.; 1972.

25. Lu A, Salabas EL, Schuth F. Magnetic nanoparticles: synthesis, protection, functionalization, and application. Angew Chem Int Ed. 2007:46:1222-44.

26. Kolhatkar AG, Jamison AC, Litvinov D, Willson RC, Lee TR. Tuning the magnetic properties of nanoparticles. Int J Mol Sci. 2013;14:15977-6009

27. Nguyen TKT, Maclean N, Mahiddine S. Mechanisms of nucleation and growth of nanoparticles in solution. Chem Rev. 2014;114:7610-30.

28. Massart R. Preparation of aqueous magnetic liquids in alkaline and acidic media. IEEE Trans Magn. 1980;17:1247-8.

29. Hong RY, Pan TT, Han YP, Li HZ, Ding J, Han S. Magnetic field synthesis of $\mathrm{Fe}_{3} \mathrm{O}_{4}$ nanoparticles used as a precursor of ferrofluids. J Magn Magn Mater. 2007;310:37-47.

30. Langevin D. Micelles and microemulsions. Annu Rev Phys Chem. 1992:43:341-69.

31. Li X, Lin E, Zhao G, Xiao T. Microemulsion formation and phase behavior of anionic and cationic surfactants with sodium dodecyl sulfate and cetyltrimethylammonium bromide. J Colloid Interface Sci. 1996;184:20-30.

32. Lopez Quintela MA, Tojo C, Blanco MC, Rio LG, Leis JR. Microemulsion dynamics and reactions in microemulsions. Curr Opin Colloid Interface Sci. 2004;9:264-78.

33. Husein MM, Nassar NN. Nanoparticle preparation using the single microemulsions scheme. Curr Nanosci. 2008;4:370-80.

34. Laurent S, Bridot JL, Elst LV, Muller RN. Magnetic iron oxide nanoparticles for biomedical applications. Future Med Chem. 2010;2:427-49.

35. Suslick KS, Choe SB, Cichowlas AA, Grinstaff MW. Sonochemical synthesis of amorphous iron. Nature. 1991;353:414-6.

36. Abu Much R, Meridor U, Frydman A, Gedanken A. Formation of a threedimensional microstructure of $\mathrm{Fe}_{3} \mathrm{O}_{4}$-poly(vinyl alcohol) composite by evaporating the hydrosol under a magnetic field. J Phys Chem. 2006:110:8194-203

37. Kim EH, Lee HS, Kwak BK, Kim BK. Synthesis of ferrofluid with magnetic nanoparticles by sonochemical method for MRI contrast agent. J Magn Magn Mater. 2005;289:328-30.

38. Wu W, He Q, Jiang C. Magnetic iron oxide nanoparticles: synthesis and surface functionalization strategies. Nanoscale Res Lett. 2008;3:397-415.

39. Huber DL. Synthesis, properties, and applications of iron nanoparticles. Small. 2005;1:482-501.

40. Vasquez M, Luna C, Morales MP, Sanz R, Serna CJ, Mijangos C. Magnetic nanoparticles: synthesis, ordering and properties. Physica B. 2004:354:71-9. 
41. Cai W, Wan J. Facile synthesis of superparamagnetic magnetite nanoparticles in liquid polyols. J Colloid Interface Sci. 2007;305:366-70.

42. Xia T, Wang J, Wu C, Meng F, Shi Z, Lian J, Feng J, Meng J. Novel complex-coprecipitation route to form high quality triethanolamine-coated $\mathrm{Fe}_{3} \mathrm{O}_{4}$ nanocrystals: their high saturation magnetizations and excellent water treatment properties. Cryst Eng Commun. 2012;14:5741-4.

43. Liu F, Zhu JH, Hou YL, Gao S. Chemical synthesis of magnetic nanocrystals: recent progress. Chin Phy B. 2013;22:107503.

44. Santoyo Salazar J, Perez L, Abril OD, Truong Phuoc L, Ihiawakrim D, Vazquez M, Jean-Marc G, Begin-Colin S, Pourroy G. Magnetic iron oxide nanoparticles in 10-40 $\mathrm{nm}$ range: composition in terms of magnetite/ maghemite ratio and effect on the magnetic properties. Chem Mater. 2011:23:1379-86.

45. Ge S, Shi X, Sun K, Li C, Uher C, Baker JR, BanaszakHoll MM, Orr BG. Facile hydrothermal synthesis of iron oxide nanoparticles with tunable magnetic properties. J Phys Chem C. 2009;113:13593-9.

46. Cai H, An X, Jun C, Li J, Wen S, Li K, Shen M, Zheng L, Zhang G, Shi $X$. Facile hydrothermal synthesis and surface functionalization of polyethyleneimine-coated iron oxide nanoparticles for biomedical applications. ACS Appl Mater Interfaces. 2013:5:1722-31.

47. Khollam YB, Dhage SR, Potdar HS, Deshpande SB, Bakare PP, Kulkarni SD, Date SK. Microwave hydrothermal preparation of submicron-sized spherical magnetite $\left(\mathrm{Fe}_{3} \mathrm{O}_{4}\right)$ powders. Mater Lett. 2002:56:571-7.

48. Li J, Shi X, Shen M. Hydrothermal synthesis and functionalization of iron oxide nanoparticles for $\mathrm{mr}$ imaging applications. Part Part Syst Charact. 2014:31:1223-37.

49. Mohammed Khawja Ansari SA, Eleonora F, Federico Alessandro R, Ilaria S, Monica A, Ornella A, Roberta C, Caterina G, Federico D. Magnetic iron oxide nanoparticles: synthesis, characterization and functionalization for biomedical applications in the central nervous system. Materials. 2019;12:465.

50. Unfried K, Albrecht C, Klotz LO, Von Mikecz A, Grether Beck S, Schins RPF. Cellular responses to nanoparticles: target structures and mechanisms. Nanotoxicology. 2007;1:52-71.

51. Toyokuni S. Iron-induced carcinogenesis: the role of redox regulation. Free Radic Biol Med. 1996;20:553-66.

52. Valko M, Leibfritz D, Moncol J, Cronin MTD, Mazur M, Telser J. Free radicals and antioxidants in normal physiological functions and human disease. J Biochem Cell Biol. 2007;39:44-84.

53. Mahmoudi M, Simchi A, Imani M, Milani AS, Stroeve P. Optimal design and characterization of superparamagnetic iron oxide nanoparticles coated with polyvinyl alcohol for targeted delivery and imaging. J Phys Chem B. 2008;112:14470-81.

54. Nel A, Xia T, Madler L, Li N. Toxic potential of materials at the nanolevel. Science. 2006;311:622-7.

55. Hafelli UO, Riffle JS, Harris Shekhawat S, Carmichael Baranauskas A, Mark F, Dailey JP, Bardenstein D. Cell uptake and in vitro toxicity of magnetic nanoparticles suitable for drug delivery. Mol Pharm. 2009;6:1417-28.

56. Elias A, Tsourkas A. Imaging circulating cells and lymphoid tissues with iron oxide nanoparticles. Hematology. 2009;1:720-6.

57. Ankamwar B, Lai TC, Huang JH, Liu RS, Hsiao M, Chen CH, Hwu YK. Biocompatibility of $\mathrm{Fe}_{3} \mathrm{O}_{4}$ nanoparticles evaluated by in vitro cytotoxicity assays using normal, glia and breast cancer cells. Nanotechnology. 2010;21:75102.

58. Bulte JWM, Douglas T, Witwer B, Zhang SC, Strable E, Lewis BK, Zywicke $H$, Mille B, Van Gelderen P, Moskowitz BM, Duncan ID, Frank JA. Magnetodendrimers allow endosomal magnetic labeling and in vivo tracking of stem cells. Nat Biotechnol. 2001:19:1141-7.

59. Veranth JM, Kaser EG, Veranth MM, Koch M, Yost GS. Cytokine responses of human lung cells (BEAS-2B) treated with micron-sized and nanoparticles of metal oxides compared to soil dusts. Particle Fibre Toxicol. 2007:4:1-18.

60. Nanotoxicology Singh N. Health \& environmental impacts. Nanomedicine. 2009;4:385-90.

61. Stevens RG, Jones DY, Micozzi MS, Taylor PR. Body iron stores and the risk of cancer. Am J Med. 1988;319:1047-52.

62. Lacava ZGM, Azevedo RB, Lacava LM, Martins EV, Garcia VAP, Rebula CA, Lemos APC, Sousa MH, Tourinho FA, Morais PC, Da Silva MF. Toxic effects of ionic magnetic builds in mice. J Magn Magn Mater. 1999;194:90-5.
63. Xie J, Liu G, Eden HS, Ai H, Chen X. Surface-engineered magnetic nanoparticle platforms for cancer imaging and therapy. Acc Chem Res. 2011:44:883-92.

64. Mahmoudi M, Hossein Hosseinkhani X, Hosseinkhani M, Boutry S, Simchi A, Shane Journeay W, KarthikeyanSubramani V, Laurent S. Magnetic resonance imaging tracking of stem cells in vivo using iron oxide nanoparticles as a tool for the advancement of clinical regenerative medicine. Chem Rev. 2011;111:253-80.

65. Sheng Nan S, Chao W, Zan Zan Z, Long HY, Venkatraman SS, Chuan $X Z$. Magnetic iron oxide nanoparticles: synthesis and surface coating techniques for biomedical applications. Chin Phys B. 2014;23:037503.

66. Gregory VL, Kelvin BG, Simon CA, Jamie RL. Transformations of nanomaterials in the environment. Environ Sci Technol. 2012;46:6893-9.

67. Tanapon P, Thomas CL, Gregoryv L, Andbel L. Partial oxidation ("aging") and surface modification decrease the toxicity of nanosized zerovalent iron. Environ Sci Technol. 2009:43:195-200.

68. Chicgoua N, Sabine C, Richard C. Nanoscale metallic iron for environmental remediation: prospects and limitations. Water Air Soil Pollut. 2012;223:1363-82.

69. Khin MM, Sreekumaran Nair A, Jagadeesh Babu V, Murugana R, Ramakrishna $S$. A review on nanomaterials for environmental remediation. Energy Environ Sci. 2012;5:8075-109.

70. Khara DG, Annika F, Nanna BH, Eva E, Poul LB, Anders B. Environmental benefits and risks of zero-valent iron nanoparticles $(n Z \mathrm{Vl})$ for in situ remediation: risk mitigation or trade-off? J Contam Hydrol. 2010;2010(118):165-83

71. Wenhui L, Mingyu W, Chunxia X, Dengfeng X, Qiyu C, Xinyue C, Xiaoyan Q, Yuemin L, Xiong X. Synthesis, surface modification, and applications of magnetic iron oxide nanoparticles. J Mater Res. 2019;34:1828-44.

72. Nan Z, Haining J, Peng Y, Jiaqi N, Farooq MU, Waseem Akram M, Udego $1 \mathrm{O}$, Handong $\mathrm{L}$, Xiaobin N. Surface modification of magnetic iron oxide nanoparticles. Nanomaterials. 2018;8:810.

73. Papell SS. Low viscosity magnetic fluid obtained by the colloidal suspension of magnetic particles. US Patent 3215572, 1965.

74. Molday RS, MacKenzie D. Immunospecific ferromagnetic iron-dextran reagents for the labeling and magnetic separation of cells. Immunol Methods. 1982;52:353-67.

75. Sreeram KJ, Indumathy R, Balachandran UN. Synthesis of iron oxide nanoparticles using chitosan and starch templates. Trans Metal Chem. 2008:33:127-31.

76. Arias $\mathrm{L}$, Reddy LH, Couvreur P. $\mathrm{Fe}_{3} \mathrm{O}_{4}$ /chitosan nanocomposite for magnetic drug targeting to cancer. J Mater Chem. 2012;22:7622-32.

77. Rekha MR, Sharma CP. Pullulan as a promising biomaterial for biomedical applications: a perspective. Trends Biomater Artif Organs. 2007;20:116-21.

78. Chatterjee J, Haik Y, Chen CJ. Modification and characterization of polystyrene-based magnetic microspheres and comparison with albuminbased magnetic microspheres. J Magn Magn Mater. 2001;225:21-9.

79. Shi X, Wang SH, Swanson SD, Ge S, Cao Z, Van Antwerp EM, Landmark $\mathrm{KL}$, Baker JR. Dendrimer-functionalized shell-crosslinked iron oxide nanoparticles for in-vivo magnetic resonance imaging of tumors. Adv Mater. 2008;20:1671-8.

80. Wang SH, Shi S, Antwerp MV, Cao Z, Swanson SD, Bi X, Baker JR. Dendrimer functionalized iron oxide nanoparticles for specific targeting and imaging of cancer cells. Adv Funct Mater. 2007;17:3043-50.

81. Aurich K, Schwalbe M, Clement JM, Weitschies W, Buske N. Polyaspartate coated magnetite nanoparticles for biomedical applications. J Magn Magn Mater. 2007;311:1-5.

82. Liang $Y Y$, Zhang LM, Jiang W, Li W. Embedding magnetic nanoparticlesinto polysaccharide-based hydrogels for magnetically assisted bioseparation. ChemPhysChem. 2007:8:2367-72.

83. Saravanan M, Bhaskar K, Mahajaran G, Pillai KS. Ultrasonically controlled release and targeted delivery of diclofenac sodium via gelatin magnetic microspheres. Int J Pharm. 2004:283:71-82

84. Kim DH, Lee SH, Im KH, Kim KN, Kim KM, Shim IB, Lee MH, Lee YK. Surface modified magnetite nanoparticles for hypertheremia: preparation, characterization and cytotoxicity studies. Curr Appl Phys. 2006;6S1:242-6.

85. Ma HL, Xu YF, Qi XR, Maitani Y, Nagai T. Superparamagnetic iron oxide nanoparticles stabilized by alginate: pharmacokinetics, tissue 
distribution, and applications in detecting liver cancers. Int J Pharm. 2008;354:217-26.

86. Li J, He Y, Sun W, Luo Y, Cai H, Pan Y, Shen M, Xia J, Shi X. Hyaluronic acid-modified hydrothermally synthesized iron oxide nanoparticles for targeted tumor MR imaging. Biomaterials. 2014;35:3666-77.

87. Hu Y, Wang R, Li J, Ding L, Wang W, Shi X, Shen M. Facile synthesis of lactobionic acid-targeted iron oxide nanoparticles with ultrahigh relaxivity for targeted magnetic resonance imaging of an orthotopic model of human hepatocellular carcinoma. Part Part Syst Charact. 2017;34:1600113.

88. Viota JL, Delgado AV, Arias JL, Duran JDG. Study of the magnetorheological response of aqueous magnetite suspensions stabilized by acrylic acid polymers. J Colloid Interface Sci. 2008;324:199-204.

89. Lin PC, Chou PH, Chen SH, Liao HK, Wang KY, Chen YJ, Lin CC. Ethylene glycol-protected magnetic nanoparticles for a multiplexed immunoassay in human plasma. Small. 2006;2:485-9.

90. Gomez-Lopera SA, Plaza RC, Delgado AV. Synthesis and characterization of spherical magnetite/biodegradable polymer composite particles. J Colloid Interface Sci. 2001;240:40-7.

91. Gomez-Lopera SA, Arias JL, Gallardo V, Delgado AV. Colloidal stability of magnetite/poly(lactic acid) core/shell nanoparticles. Langmuir. 2006;22:2816-21.

92. Hamoudeh M, Faraj AA, Canet-Soulas E, Bessueille F, Leonard D, Fessi H. Elaboration of PLLA-based superparamagnetic nanoparticles: characterization, magnetic behaviour study and in vitro relaxivity evaluation. Int J Pharm. 2007;338:248-57.

93. Kumagai M, Imai Y, Nakamura T, Yamasaki Y, Sekino M, Ueno S, Hanaoka K, Kikuchi K, Nagano T, Kaneko E, Shimokado K, Kataoka K. Iron hydroxide nanoparticles coated with poly(ethylene glycol)-poly(aspartic acid) block copolymer as novel magnetic resonance contrast agents for in vivo cancer imaging. Colloids Surf B. 2007:56:174-81.

94. Fan QL, Neoh KG, Kang ET, Shuter B, Wang SC. Solvent-free atom transfer radical polymerization for the preparation of poly(poly(ethyleneglycol) monomethacrylate)-grafted $\mathrm{Fe}_{3} \mathrm{O}_{4}$ nanoparticles: synthesis, characterization and cellular uptake. Biomaterials. 2007:28:5426-36

95. Ren J, Hong HY, Ren TB, Teng XR. Preparation and characterization of magnetic PLA-PEG composite particles. Mater Lett. 2005;59:2655-8.

96. Nasongkla N, Bey E, Ren JM, Ai H, Khemtong C, Guthi JS, Chin SF, Sherry AD, Boothman DA, Gao JM. Multifunctional polymeric micelles as cancer-targeted, MRI-ultrasensitive drug delivery systems. Nano Lett. 2006:6:2427-30.

97. Okassa LN, Marchais H, Douziech Eyrolles L, Cohen Jonathan S, Souce $M$, Dubois $P$, Chourpa I. Development and characterization of submicron poly(D, L-lactide-co-glycolide) particles loaded with magnetite/ maghemite nanoparticles. Int J Pharm. 2005;302:187-96.

98. Perez-Artacho B, Gallardo V, Ruiz MA, Arias JL. Maghemite/poly(D, L-lactide-co-glycolyde) composite nanoplatform for therapeutic applications. J Nanoparticle Res. 2012:14:1-10

99. Arias JL, Gallardo V, Ruiz MA, Delgado AV. Magnetite/ poly(alkylcyanoacrylate) (core/shell) nanoparticles as 5-fluorouracil delivery systems for active targeting. Eur J Pharm Biopharm. 2008;69:54-63.

100. Arias JL, Ruiz MA, Gallardo V, Delgado AV. Tegafur loading and release properties of magnetite/poly(alkylcyanoacrylate) (core/shell) nanoparticles. J Control Release. 2008;125:50-8.

101. Santos DP, Ruiz MA, Gallardo V, Zanoni MVB, Arias JL. Multifunctional antitumor magnetite/chitosan-L-glutamic acid (core/shell) nanocomposites. J Nanoparticle Res. 2011;13:4311-23.

102. Flesch C, BourgeatLami E, Mornet S, Duguet E, Delaite C, Dumas P. Synthesis of colloidal superparamagnetic nanocomposites by grafting poly $(\boldsymbol{\epsilon}$-caprolactone) from the surface of organosilane-modified maghemite nanoparticles. J Polym Sci Part A Polym Chem. 2005;43:3221-31.

103. Yang Y, Park SB, Yoon HG, Huh YM, Haam S. Preparation of poly $\varepsilon$-caprolactone nanoparticles containing magnetite for magnetic drug carrier. Int J Pharm. 2006:324:185-90.

104. Arias JL, Lopez Viota M, Ruiz MA, Lopez Viota J, Delgado AV. Development of carbonyl iron/ethylcellulose core/shell nanoparticles for biomedical applications. Int J Pharm. 2007;339:237-45.
105. Arias JL, Lopez Viota M, Delgado AV, Ruiz MA. Iron/ethylcellulose (core/ shell) nanoplatform loaded with 5-fluorouracil for cancer targeting. Colloids Surf B. 2010;77:111-6.

106. Yihui X, Rachid S, Suzana Nunes P. Synthesis and characterization of polystyrene coated iron oxide nanoparticles and asymmetric assemblies by phase inversion. J Appl Polym Sci. 2015;132:41368.

107. Song HT, Choi JS, Huh YM, Kim S, Jun YW, Suh JS, Cheon J. Surface modulation of magnetic nanocrystals in the development of highly efficient magnetic resonance probes for intracellular labeling. J Am Chem Soc. 2005;127:9992-3.

108. Duan H, Nie S. Cell-penetrating quantum dots based on multivalent and endosome-disrupting surface coatings. J Am Chem Soc. 2007:129:3333-8.

109. Yee C, Kataby G, Ulman A, Prozorov T, White H, King A, Rafailovich M, Sokolov J, Gedanken A. Self-assembled monolayers of alkanesulfonic and -phosphonic acids on amorphous iron oxide nanoparticles. Langmuir. 1999;15:7111-5.

110. Sahoo Y, Pizem H, Fried T, Golodnitsky D, Burstein L, Sukenik CN, Markovich G. Alkyl phosphonate/phosphate coating on magnetite nanoparticles: a comparison with fatty acids. Langmuir. 2001;17:7907-11.

111. Zhang C, Wangler B, Morgenstern B, Zentgraf H, Eisenhut M, Untenecker H, Kruger R, Huss R, Seliger C, Semmler W, Kiessling F. Silica- and alkoxysilane-coated ultrasmall superparamagnetic iron oxide particles: a promising tool to label cells for magnetic resonance imaging. Langmuir. 2007;23:1427-34

112. Cho SJ, Jarrett BR, Louie AY, Kauzlarich SM. Gold-coated iron nanoparticles: a novel magnetic resonance agent for $\mathrm{T} 1$ and $\mathrm{T} 2$ weighted imaging. Nanotechnology. 2006;17:640-4.

113. Li J, Hu Y, Yang J, Wei P, Sun W, Sun M, Shen M, Zhang G, Shi X. Hyaluronic acid-modified $\mathrm{Fe}_{3} \mathrm{O}_{4} @ \mathrm{Au}$ core/shell nanostars for multimodal imaging and photothermal therapy of tumors. Biomaterials. 2015;38:10-21.

114. Hu Y, Wang R, Wang S, Ding L, Li J, Luo Y, Wang X, Shen M, Shen X. Multifunctional $\mathrm{Fe}_{3} \mathrm{O}_{4} @$ Au core/shell nanostars: a unique platform for multimode imaging and photothermal therapy of tumors. Sci Rep. 2016:6:28325.

115. Levy L, Sahoo Y, Kim KS, Bergey EJ, Prasad PN. Nanochemistry: synthesis and characterization of multifunctional nanoclinics for biological applications. Chem Mater. 2002;14:3715-21.

116. Qin J, Asempah I, Laurent S, Fornara A, Muller R, Muhammed M. Injectable superparamagnetic ferrogels for controlled release of hydrophobic drugs. Adv Mater. 2009:21:1354-7.

117. Smith JE, Medley CD, Tang Z, Shangguan D, Lofton C, Tan W. Aptamerconjugated nanoparticles for the collection and detection of multiple cancer cells. Anal Chem. 2007;79:3075-82.

118. Jing Y, Moore LR, Williams PS, Chalmers JJ, Farag SS, Bolwell B. Blood progenitor cell separation from clinical leukapheresis product by magnetic nanoparticle binding and magnetophoresis. Biotechnol Bioeng. 2007:96:1139-54.

119. Chiang C, Chen C, Chang L. Purification of recombinant enhanced green fluorescent protein expressed in Escherichia coli with new immobilized metal ion affinity magnetic absorbents. J Chromatogr B. 2008:864:116-22

120. Fornara A, Johansson P, Petersson K, Gustafsson S, Qin J, Olsson E, Ilver D, Krozer A, Muhammed M, Johansson C. Tailored magnetic nanoparticles for direct and sensitive detection of biomolecules in biological samples. Nano Lett. 2008:8:3423-8.

121. Budde MD, Frank JA. Magnetic tagging of therapeutic cells for MRI. J Nucl Med. 2009;50:171-4.

122. Arbab AS, Liu W, Frank JA. Cellular magnetic resonance imaging: current status and future prospects. Expert Rev Med Devices. 2006;3:427-39.

123. Bhirde A, Xie J, Swierczewska M, Chen X. Nanoparticles for cell labelling. Nanoscale. 2011;3:142-53.

124. Magro M, Baratella D, Bonaiuto E, de A Roger J, Vianello F. New perspectives on biomedical applications of iron oxide nanoparticles. Curr Med Chem. 2018:25:540-55.

125. Arruebo M, Fernandez Pacheco R, Ibarra MR, Santamaria J. Magnetic nanoparticles for drug delivery. Nano Today. 2007;2:22-32.

126. Cao $\mathrm{D}, \mathrm{He}$, Hu N. Electrochemical biosensors utilising electron transfer in heme proteins immobilised on $\mathrm{Fe}_{3} \mathrm{O}_{4}$ nanoparticles. Analyst. 2003:128:1268-74. 
127. Gao L, Zhuang J, Nie L, Zhang J, Zhang Y, Gu N, Wang T, Jeng J, Yang D, Perrett $S$, Yan X. Intrinsic peroxidase-like activity of ferromagnetic nanoparticles. Nat Nanotechnol. 2007;2:577-83.

128. Rossi LM, Quach AD, Rosenzweig Z. Glucose oxidase-magnetite nanoparticle bioconjugate for glucose sensing. Anal Bioanal Chem. 2004;380:606-13.

129. El-Boubbou K. Magnetic iron oxide nanoparticles as drug carriers: preparation, conjugation and delivery. Nanomedicine. 2018;13:929.

130. El-Boubbou K. Magnetic iron oxide nanoparticles as drug carriers: clinical relevance. Nanomedicine. 2018;13:953.

131. McBain SC, Yiu HHP, Dobson J. Magnetic nanoparticles for gene and drug delivery. Int J Nanomed. 2008;3:169-80.

132. Shinkai M. Functional magnetic particles for medical application. J Biosci Bioeng. 2002;94:606-13.

133. Mornet S, Vasseur S, Grasset F, Veverka P, Goglio G, Demourgues A. In: Meeting of the European-Materials-Research-Society. Strasbourg: Pergamon-Elsevier Science Ltd; 2005. p. 237.

134. Lanza GM, Winter P, Caruthers S, Schmeider A, Crowder K, Morawsk A. Novel paramagnetic contrast agents for molecular imaging and targeted drug delivery. Curr Pharm Biotechnol. 2004;5:495-507.

135. Atri M. New technologies and directed agents for applications of cancer imaging. J Clin Oncol. 2006;24:3299-308.

136. Martinkova P, Brtnicky M, Kynicky J, Pohanka M. Iron oxide nanoparticles: innovative tool in cancer diagnosis and therapy. Adv Healthc Mater. 2017;7:1700932.

137. Park JH, Von Maltzahn G, Ruoslahti E, Bhatia SN, Sailor MJ. Micellar hybrid nanoparticles for simultaneous magnetofluorescent imaging and drug delivery. Angew Chem Int Ed Engl. 2008;47:7284-8.

138. Santra S, Kaittanis C, Grimm J, Perez JM. Drug/dye-loaded, multifunctional iron oxide nanoparticles for combined targeted cancer therapy and dual optical/magnetic resonance imaging. Small. 2009:5:1862-8.

139. Quan Q, Xie J, Gao H, Yang M, Zhang F, Liu G, Lin X, Wang A, Eden HS, Zhang $G$, Chen X. HSA coated iron oxide nanoparticles as drug delivery vehicles for cancer therapy. Mol Pharm. 2011;8:1669-76.

140. Yu MK, Jeong YY, Park J, Park S, Kim JW, Min JJ, Kim K, Jon S. Drugloaded superparamagnetic iron oxide nanoparticles for combined cancer imaging and therapy in vivo. Angew Chem. 2008;47:5362-5.

141. Tietze R, Lyer S, Durr S, Alexiou C. Nanoparticles for cancer therapy using magnetic forces. Nanomedicine. 2012;7:447-57.

142. Pack DW, Hoffman AS, Pun S, Stayton PS. Design and development of polymers for gene delivery. Nat Rev Drug Discov. 2005;4:581-93.

143. Neuberger T, Schopf B, Hofmann H, Hofmann M, Von Rechenberg B. Superparamagnetic nanoparticles for biomedical applications: possibilities and limitations of a new drug delivery system. J Magn Magn Mater. 2005;293:483-96

144. Subramani K, Hosseinkhani H, Khraisat A, Hosseinkhani M, Pathak Y. Targeting nanoparticles as drug delivery systems for cancer treatment. Curr Nanosci. 2009;5:135-40.

145. Mintzer MA, Simanek EE. Nonviral vectors for gene delivery. Chem Rev. 2009;109:259-302.

146. Gallia M, Guerrinib A, Cauteruccioa S, Thakarea P, Dovaa D, Orsinic F, Arosioc P, Carraraa C, Sangregoriode C, Lascialfarice A, Maggioni D, Licandro E. Superparamagnetic iron oxide nanoparticles functionalized by peptide nucleic acids. RSC Adv. 2017;7:15500-12.

147. Sun C, Lee JSH, Zhang MQ. Magnetic nanoparticles in MR imaging and drug delivery. Adv Drug Deliv Rev. 2008;60:1252-65.

148. Pankhurst QA, Connolly J, Jones SK, Dobson J. Applications of magnetic nanoparticles in biomedicine. J Phys D Appl Phys. 2003;36:167-81.

149. Bhirde A, Guo N, Chen X. Targeted Nanoprobes Reveal Early Time Point Kinetics In Vivo by Time-Resolved MRI. Theranostics. 2011;1:274-6.

150. Weissleder R, Cheng HC, Bogdanova A, Bogdanov A. Magnetically labelled cells can be detected by MR imaging. J Magn Reson Imaging. 1997;7:258-63.

151. Louie AY, Huber MM, Ahrens ET, Rothbacher U, Moats R, Jacobs RE, Fraser SE, Meade TJ. In vivo visualization of gene expression using magnetic resonance imaging. Nat Biotechnol. 2000;18:321-5.

152. Xie J, Huang J, Li X, Sun S, Chen X. Iron oxide nanoparticle platform for biomedical applications. Curr Med Chem. 2009;16:1278-94.

153. Mikhaylov G, Mikac U, Magaeva AA, Itin VI, Naiden EP, Psakhye I, Babes L, Reinheckel T, Peters C, Zeiser R, Bogyo M, Turk V, Psakhye SG, Turk B, Vasiljeva O. Ferri-liposomes as an MRI-visible drug-delivery system for targeting tumours and their microenvironment. Nat Nanotechnol. 2011;6:594-602.

154. Xavier M, Montet-Abou K, Reynolds F, Weissleder R, Josephson L. Nanoparticle imaging of integrins on tumor cells. Neoplasia. 2006;8:214-22.

155. Chakravarty R, Chakraborty S, Dash A. Molecular imaging of breast cancer: role of RGD peptides. Mini Rev Med Chem. 2015;15:1073-94.

156. Rosen JE, Chan L, Shieh DB, Gu FX. Iron oxide nanoparticles for targeted cancer imaging and diagnostics. Nanomedicine. 2012;8:275-90.

157. Lewin M, Carlesso N, Ching-Hsuan T, Xiao-Wu T, David C, David TS, Weissleder R. Tat peptide-derivatized magnetic nanoparticles allow in vivo tracking and recovery of progenitor cells. Nat Biotechnol. 2000:18:410-4

158. Jasmin GTS, Torres de Souza G, Ruy Andrade L, Rosado-de-Castro PH, Mendez-Otero R, Campos de Carvalho AC. Tracking stem cells with superparamagnetic iron oxide nanoparticles: perspectives and considerations. Int J Nanomed. 2017:12:779-93.

159. Ho-Taek S, Jin-sil C, Yong-Min H, Sungjun K, Young-wook J, Jin-Suck $\mathrm{S}$, Jinwoo C. Surface modulation of magnetic nanocrystals in the development of highly efficient magnetic resonance probes for intracellular labeling. J Am Chem Soc. 2005;17:9992-3.

160. Chen X. Molecular imaging probes for cancer research. Molecular imaging probes for cancer research. World Scientific. 2012.

161. Sun C, Veiseh O, Gunn J, Fang C, Hansen S, Lee D, Sze R, Ellenbogen RG, Olson J, Zhang M. In vivo MRI detection of gliomas by chlorotoxin-conjugated superparamagnetic nanoprobes. Small. 2008:4:372-9.

162. Portet D, Denizot B, Rump E, Lejeune JJ, Jallet P. Nonpolymeric coatings of iron oxide colloids for biological use as magnetic resonance imaging contrast agents. J Colloid Interface Sci. 2001;238:37-42.

163. Mahmoudi M, Milani AS, Stroeve P. Synthesis, surface architecture and biological response of superparamagnetic iron oxide nanoparticles for application in drug delivery: a review. Int J Biomed Nanosci Nanotechnol. 2010;1:164.

164. Mahmoudi M, Simchi A, Imani M, Hafeli UO. Superparamagnetic iron oxide nanoparticles with rigid cross-linked polyethylene glycol fumarate coating for application in imaging and drug delivery. J Phys Chem C. 2009;113:8124-31.

165. Hosein H, Debnath S, Liu G, Strongin DR. A general method for copper-catalyzed arylation of arene $\mathrm{C}-\mathrm{H}$ bonds. In: ACS symposium series (Biomolecular catalysis), Chapter 8, vol. 986. 2008. p. 144-54.

166. Mahmoudi M, Simchi A, Vali H, Imani M, Shokrgozar MA, Azadmanesh $\mathrm{K}$, Azari F. Cytotoxicity and cell cycle effects of bare and poly(vinyl alcohol)-coated iron oxide nanoparticles in mouse fibroblasts. Adv Eng Mater. 2009;11:243-50.

167. Braun S, Oppermann H, Mueller A, Renner C, Hovhannisyan A, BaranSchmidt R, Gebhardt R, Hipkiss A, Thiery J, Meixensberger J, Gauntiz F. Hedgehog signaling in glioblastoma multiforme. Cancer Biol Ther. 2012;13:487-95.

168. Stupp R, Mason WP, Van Den Bent MJ, Weller M, Fisher B, Taphoorn MJ, Belanger K, Brandes AA, Marosi C, Bogdahn U, Curschmann J, Janzer RC, Ludwin SK, Gorlia T, Allgeier A, Lacombe D, Cairncross $J G$, Eisenhauer E, Mirimanoff RO. Radiotherapy plus concomitant and adjuvant temozolomide for glioblastoma. N Engl J Med. 2005;352:987-96

169. Hou LC, Veeravagu A, Hsu AR, Tse VC. Recurrent glioblastoma multiforme: a review of natural history and management options. Neurosurg Focus. 2006;20:E5

170. Kumar M, Medarova Z, Pantazopoulos P, Dai G, Moore A. Novel membrane-permeable contrast agent for brain tumor detection by MRI. Magn Reson Med. 2010;63:617-24.

171. Hadjipanayis CG, Machaidze R, Kaluzova M, Wang L, Schuette AJ, Chen $\mathrm{H}, \mathrm{Wu}$ X, Mao H. EGFRvIll antibody conjugated iron oxide nanoparticles for MRI guided convection-enhanced delivery and targeted therapy of glioblastoma. Cancer Res. 2010;70:6303-12.

172. Fajardo LF. Pathological effects of hyperthermia in normal tissues. Cancer Res. 1984:44:4825-35.

173. Van Landeghem FKH, Maier-Hauff K, Jordan A, Hoffmann KT, Gneveckow U, Scholz R, Thiesen B, Bruck W, Von Deimling A. Postmortem studies in glioblastoma patients treated with thermotherapy using magnetic nanoparticles. Biomaterials. 2009;30:52-7. 
174. Pourmand S, Abdouss M, Rashidi A. Fabrication of nanoporous graphene by chemical vapor deposition (CVD) and its application in oil spill removal as a recyclable nanosorbent. J Ind Eng Chem. 2015;22:8-18

175. Lahann J. Environmental nanotechnology: nanomaterials clean up. Nat Nanotechnol. 2008;3:320-1.

176. Deng D, Prendergast DP, MacFarlane J, Bagatin R, Stellacci F, Gschwend PM. Hydrophobic meshes for oil spill recovery devices. ACS Appl Mater Interfaces. 2013;5:774-81.

177. Zhu Q, Tao F, Pan Q. Fast and selective removal of oils from water surface via highly hydrophobic core-shell $\mathrm{Fe}_{2} \mathrm{O}_{3} @ \mathrm{C}$ nanoparticles under magnetic field. ACS Appl Mater Interfaces. 2010;2:3141-6.

178. Thanikaivelan P, Narayanan NT, Pradhan BK, Ajayan PM. Collagen based magnetic nanocomposites for oil removal applications. Sci Rep. 2012;2:230.

179. Calcagnile P, Fragouli D, Bayer IS, Anyfantis GC, Martiradonna L, Cozzoli $P D$, Cingolani R, Athanassiou A. Magnetically driven floating foams for the removal of oil contaminants from water. ACS Nano. 2012;6:5413-9.

180. Kudr J, Haddad Y, Richtera L, Heger Z, Cernak M, Adam V, Zitka O. Magnetic nanoparticles: from design and synthesis to real world applications. Nanomaterials. 2017;7:243

181. Ge B, Zhang Z, Zhu X, Ren G, Men X, Zhou XA. A magnetically super hydrophobic bulk material for oil removal. Colloids Surf $A$ 2013;429:129-33.

182. Subrati A, Mondal S, Ali M, Alhindi A, Ghazi R, Abadala A, Reinalda D, Alhassan S. Developing hydrophobic graphene foam for oil spill cleanup. Ind Eng Chem Res. 2017;56:6945-51.

183. Hsu R-S, Chang W-H, Lin J-J. Nanohybrids of magnetic iron-oxide particles in hydrophobic organoclays for oil recovery. ACS Appl Mater Interfaces. 2010;2:1349-54.

184. Pavia-Sanders A, Zhang S, Flores JA, Sanders JE, Raymond JE, Wooley $\mathrm{KL}$. Robust magnetic/polymer hybrid nanoparticles designed for crude oil entrapment and recovery in aqueous environments. ACS Nano. 2013;7:7552-61.

185. Wang B, Liang W, Guo Z, Liu W. Biomimetic super-lyophobic and superlyophilic materials applied for oil/water separation: a new strategy beyond nature. Chem Soc Rev. 2015;44:336-61.

186. Yoon TJ, Lee W, Oh YS, Lee JK. Magnetic nanoparticles as a catalyst vehicle for simple and easy recycling. New J Chem. 2003;27:227-9.

187. Latham AH, Williams ME. Controlling transport and chemical functionality of magnetic nanoparticles. Acc Chem Res. 2008;41:411-20.

188. Rangheard C, De Julian Fernandez C, Phua PH, Hoorn J, Lefort L, De Vries JG. At the frontier between heterogeneous and homogeneous catalysis: hydrogenation of olefins and alkynes with soluble iron nanoparticles. Dalton Trans. 2010;39:8464-71.

189. Phua PH, Lefort L, Boogers JAF, Tristany M, De Vries JG. Soluble iron nanoparticles as cheap and environmentally benign alkene and alkyne hydrogenation catalysts. Chem Commun. 2009;25:3747-9.

190. Wang Z, Shen B, Aihua Z, He N. Synthesis of $\mathrm{Pd} / \mathrm{Fe}_{3} \mathrm{O}_{4}$ nanoparticlebased catalyst for the cross-coupling of acrylic acid with iodobenzene. Chem Eng J. 2005;113:27-34.

191. Rossi LM, Silva FP, Vono LLR, Kiyohara PK, Duarte EL, Itri R, Landers R, Machado G. Superparamagnetic nanoparticle-supported palladium: a highly stable magnetically recoverable and reusable catalyst for hydrogenation reactions. Green Chem. 2007:9:379-85.

192. Zeng T, Chen WW, Cirtiu CM, Moores A, Song G, Li C-J. Fe $\mathrm{O}_{4}$ nanoparticles: a robust and magnetically recoverable catalyst for three-component coupling of aldehyde, alkyne and amine. Green Chem. 2010;12:570-3.

193. Zhang ZH, Lu HY, Yang SH, Gao JW. Synthesis of 2,3-dihydroquinazolin$4(1 \mathrm{H})$-ones by three-component coupling of isatoic anhydride, amines, and aldehydes catalyzed by magnetic $\mathrm{Fe}_{3} \mathrm{O}_{4}$ nanoparticles in water. J Comb Chem. 2010;12:643-6.

194. Sreedhar B, Kumar AS, Reddy PS. Magnetically separable $\mathrm{Fe}_{3} \mathrm{O}_{4}$ nanoparticles: an efficient catalyst for the synthesis of propargylamines. Tetrahedron Lett. 2010;51:1891-5.

195. Movassagh B, Talebsereshki F. Efficient one-pot synthesis of b-acetamido carbonyl compounds using $\mathrm{Fe}_{3} \mathrm{O}_{4}$ nanoparticles. Helv Chem Acta. 2013:96:1943-7.

196. Kassaee MZ, Motamedi E, Movassagh B, Poursadeghi S. plarpoerncatalyzed formation of $\mathrm{C}-\mathrm{Se}$ and $\mathrm{C}-\mathrm{Te}$ bonds through cross coupling of aryl Halides with $\mathrm{Se}(0)$ and $\mathrm{Te}(0) /$ nano- $\mathrm{Fe}_{3} \mathrm{O}_{4} @ \mathrm{GO}$. Synthesis. 2013:45:2337-42.

197. Cantillo D, Baghbanzadeh M, Kappe CO. In situ generated iron oxide nanocrystals as efficient and selective catalysts for the reduction of nitroarenes using a continuous flow method. Angew Chem Int Ed. 2012:51:10190-3.

198. Nagajyothi PC, Pandurangan M, Kim DH, Sreekanth TVM, Shim J. Green synthesis of iron oxide nanoparticles and their catalytic and in vitro anticancer activities. J Clust Sci. 2017;28:245-57.

199. Pandi K, Periyasamy S, Viswanathan N. Remediation of fluoride from drinking water using magnetic iron oxide coated hydrotalcite/chitosan composite. Int J Biol Macromol. 2017;104:1569-77.

200. Wang CB, Zhang WX. Synthesizing nanoscale iron particles for rapid and complete dechlorination of TCE and PCBs. Environ Sci Technol. 1997:31:2154-6.

201. Mondal K, Jegadeesan G, Lalvani SB. Removal of selenate by Fe and NiFe nanosized particles. Ind Eng Chem Res. 2004;43:4922-34.

202. Gui M, Ormsbee LE, Bhattacharyya D. Reactive functionalized membranes for polychlorinated biphenyl degradation. Ind Eng Chem Res. 2013;52:10430-40.

203. Olegario JT, Yee N, Miller M, Sczepaniak J, Manning B. Reduction of $\mathrm{Se}(\mathrm{VI})$ to Se(-II) by zerovalent iron nanoparticle suspensions. J Nanoparticle Res. 2010;12:2057-68.

204. Yoon IH, Kim KW, Bang S, Kim MG. Reduction and adsorption mechanisms of selenate by zero-valent iron and related iron corrosion. Appl Catal B Environ. 2011:104:185-92.

205. Huang YH, Peddi PK, Tang C, Zeng H, Teng X. Hybrid zero-valent iron process for removing heavy metals and nitrate from flue-gas-desulfurization waste water. Sep Purif Technol. 2013;118:690-8.

206. Wu J, Zhu H, Liu G, Tan L, Hu X, Chen C, Alharbi NS, Hayat T, Tan X. Fabrication of core-shell CMNP@PmPD nanocomposite for efficient As(V) adsorption and reduction. ACS Sustain Chem Eng. 2017;5:4399-407.

207. Mou F, Guan J, Ma H, Xu L, Shi W. Magnetic iron oxide chestnutlike hierarchical nanostructures: preparation and their excellent arsenic removal capabilities. ACS Appl Mater Interfaces. 2012:4:3987-93.

\section{Publisher's Note}

Springer Nature remains neutral with regard to jurisdictional claims in published maps and institutional affiliations.

Ready to submit your research? Choose BMC and benefit from

- fast, convenient online submission

- thorough peer review by experienced researchers in your field

- rapid publication on acceptance

- support for research data, including large and complex data types

- gold Open Access which fosters wider collaboration and increased citations

- maximum visibility for your research: over 100M website views per year

At BMC, research is always in progress.

Learn more biomedcentral.com/submissions 